\title{
Involvement of the Thalamic Parafascicular Nucleus in Mesial Temporal Lobe Epilepsy
}

\author{
Mélanie Langlois, ${ }^{1}$ Pierre-Olivier Polack, ${ }^{3}$ Hélène Bernard, ${ }^{1}$ Olivier David, ${ }^{2}$ Stéphane Charpier, ${ }^{3}$ Antoine Depaulis, ${ }^{1}$ \\ and Colin Deransart ${ }^{1}$ \\ ${ }^{1}$ Equipe 9, Dynamique des Réseaux Synchrones Epileptiques, and 2Equipe 5, Neuroimagerie Fonctionnelle et Métabolique, Grenoble Institut des \\ Neurosciences, Institut National de la Santé et de la Recherche Médicale U 836-Université Joseph Fourier-Commisariat à l'Energie Atomique Centre \\ Hospitalier Universitaire, 38700 La Tronche, France, and ${ }^{3}$ Centre de Recherche de l'Institut du Cerveau et de la Moelle Épinière, Université Pierre et Marie \\ Curie/Institut National de la Santé et de la Recherche Médicale, Unité Mixte de Recherche-S 975, Centre National de la Recherche Scientifique Unité Mixte \\ de Recherche 7225, Hôpital Pitié-Salpêtrière, 75013 Paris, France
}

\begin{abstract}
Mesial temporal lobe epilepsy (MTLE) is characterized by focal seizures, associated with hippocampal sclerosis, and often resistance to antiepileptic drugs. The parafascicular nucleus (PF) of the thalamus is involved in the generation of physiological oscillatory rhythms. It receives excitatory inputs from the cortex and inhibitory inputs from the basal ganglia, a system implicated in the control of epileptic seizures. The aim of this study was to examine the involvement of the PF in the occurrence of hippocampal paroxysmal discharges (HPDs) in a chronic animal model of MTLE in male mice. We recorded the local field potential (LFP) and the extracellular and intracellular activity of hippocampal and PF neurons during spontaneous HPDs in vivo. The end of the HPDs was concomitant with a slow repolarization in hippocampal neurons leading to an electrical silence. In contrast, it was associated in the PF with a transient increase in the power of the $10-20 \mathrm{~Hz}$ band in LFPs and a depolarization of PF neurons resulting in a sustained firing. We tested the role of the PF in the control of HPDs by single $130 \mathrm{~Hz}$ electrical stimulation of this nucleus and bilateral intra-PF injection of $\mathrm{NMDA}_{\text {and }} \mathrm{GABA}_{\mathrm{A}}$ antagonist and agonist. High-frequency PF stimulation interrupted ongoing HPDs at an intensity devoid of behavioral effects. NMDA antagonist and

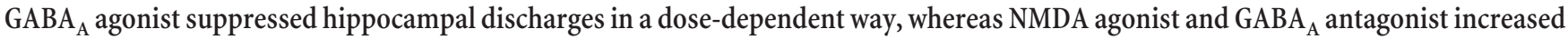
HPDs. Altogether, these data suggest that the PF nucleus plays a role in the modulation of MTLE seizures.
\end{abstract}

\section{Introduction}

The parafascicular nucleus ( $\mathrm{PF})$ of rodents, also called centromedian/parafascicular complex $(\mathrm{CM} / \mathrm{PF})$ in primates, belongs to the intralaminar system of the thalamus. Its input-output connectivity confers to this structure a key position to interfere with both cortical and basal ganglia functions. Indeed, the PF receives afferent fibers from the somatosensory and motor cortices, reticular thalamic nucleus (nRT), zona incerta, entopeduncular nucleus, substantia nigra pars reticulata $(\mathrm{SNr})$, mesencephalic reticular formation, and pedunculopontine nucleus and sends glutamatergic projections to motor, somatosensory, and entorhinal cortices and to subcortical targets, such as the striatum, subthalamic nucleus, and SNr (Berendse and Groenewegen, 1991; Groenewegen and Berendse, 1994; Mouroux et al., 1995; Deschênes et al., 1996; Van der Werf et al., 2002; Smith et al., 2004). The PF participates

Received March 4, 2010; revised Sept. 24, 2010; accepted Sept. 30, 2010.

This work was supported by the Institut National de la Santé et de la Recherche Médicale, the Agence Nationale de la Recherche (ANR-06-NEURO-005-01), and the Région Rhone-Alpes (Cluster Handicap, Vieillissement, et Neurosciences). We thank Dr. Isabelle Guillemain for critical reading of this manuscript and Anne-Marie Godeheu for histological processing. M.L. received a PhD fellowship from the Ministère Français de la Recherche.

Correspondence should be addressed to Colin Deransart, Equipe 9, Dynamique des Réseaux Synchrones Epileptiques, Centre de recherche Inserm U 836-UJF-CEA-CHU, Grenoble Institut des Neurosciences, Université Joseph Fourier, Bâtiment Edmond J. Safra, Domaine de la Merci, 38700 La Tronche Cedex, France. E-mail: colin.deransart@ ujf-grenoble.fr.

DOI:10.1523/JNEUROSCI.1109-10.2010

Copyright $\odot 2010$ the authors $\quad 0270-6474 / 10 / 3016523-13 \$ 15.00 / 0$ in cognitive (sleep wake cycle, reward mechanisms), sensory, and motor processes (Pavlides et al., 1987; Van der Werf et al., 2002; Saadé et al., 2007) as well as sensorimotor coordination (Liu et al., 2008). Recent clinical studies showed that deep brain stimulation (DBS) of the CM/PF improves behavioral and motor processes in patients with traumatic brain injuries (Schiff et al., 2007) and has therapeutic effects in severe generalized epileptic syndromes (Velasco et al., 2000, 2001, 2002, 2006). However, its effect on epilepsies such as the mesial temporal lobe epilepsy (MTLE) has never been tested (Cendes et al., 2002). MTLE is a focal epilepsy syndrome, with recurrent seizures mostly confined to the hippocampus and ipsilateral temporal lobe. Its is associated with a unilateral hippocampal sclerosis, characterized by an extensive neuronal loss in the CA1 and CA3 regions and the hilus of the dentate gyrus, a reactive gliosis, and strong neuroplasticity (Engel, 1996; Wieser, 2004). Most patients with MTLE become resistant to antiepileptic drugs (Engel, 1996; Cendes et al., 2002), and surgical resection of the sclerotic temporal lobe has become an alternative therapy (Ojemann, 1987; Chabardès et al., 2005).

Here, we test the hypothesis that the PF could control focal epileptic seizures, using a recently characterized mouse model of MTLE. In this model, unilateral intrahippocampal injection of kainic acid (KA) initially induces a nonconvulsive focal status epilepticus followed by a latent period of approximately 2 weeks, during which recurrent spontaneous hippocampal paroxysmal discharges (HPDs) and hippocampal sclerosis progressively de- 
velop (Suzuki et al., 1995; Riban et al., 2002). Hippocampal seizures sporadically spread to the cerebral cortex and are resistant to most antiepileptic drugs (Riban et al., 2002). Altogether, this murine model reproduces most of electroclinical, histological, and pharmacological features of MTLE. To examine the correlated changes occurring in the networks and neurons of the PF and hippocampus during MLTE, we performed in this model in vivo local field potential (LFP) recordings as well as extracellular and intracellular recordings from the hippocampus and $\mathrm{PF} n u-$ cleus. The putative remote control of hippocampal seizures by the PF nucleus was further investigated by testing the effects of $130 \mathrm{~Hz}$ stimulations and pharmacological manipulations of this nucleus on the occurrence of hippocampal paroxysms.

\section{Materials and Methods}

Animals. Experiments were performed on 63 8-week-old C57BL/6 male mice (Janvier) weighing 26-35 g, housed in individual cages with food and water ad libitum, and kept in a $12 \mathrm{~h}$ light/dark cycle. All animal experimentations were performed in accordance with the rules of the European Committee Council Directive of November 24, 1986 (86/609/ EEC), and all procedures were approved by the local department of the veterinarian services for the use and care of animals (agreement \#380612) as well as by the ethical committees of our institutes. All efforts were made to minimize animal suffering and reduce the number of animals used in each series of experiments.

Freely moving experiments. Mice were stereotaxically injected under general anesthesia ( $4 \%$ chloral hydrate in $0.9 \% \mathrm{NaCl} ; 10 \mathrm{ml} / \mathrm{kg}$, i.p.) with $50 \mathrm{nl}$ of a $20 \mathrm{~mm}$ solution of $\mathrm{KA}$ (Sigma) in $0.9 \% \mathrm{NaCl}$ (i.e., $1 \mathrm{nmol}$ ) into the right dorsal hippocampus [anteroposterior (AP), -1.9 ; mediolateral (ML), -1.5 ; dorsoventral (DV), $-2 \mathrm{~mm}$ ] with bregma as the reference (Paxinos and Franklin, 2001), using a stainless-steel cannula [outer diameter (o.d.), $0.28 \mathrm{~mm}$; Cortat SA] connected to a $0.5 \mu \mathrm{l}$ microsyringe (Hamilton) via PE20 tubing filled with distilled water. Each injection was performed over 1 min using a micropump (CMA/100; Carnegie Medicin) as in previous studies (Riban et al., 2002; Heinrich et al., 2006). At the end of the injection, the cannula was left in place for an additional $1 \mathrm{~min}$ period to limit reflux along the cannula track.

After intrahippocampal injection, all mice were implanted with (1) two monopolar surface electrodes placed over the left and right frontoparietal cortex for pharmacological experiments or a bipolar electrode within the right frontal sensorimotor cortex (AP, +1.4; ML, -1.6; DV, $-2 \mathrm{~mm}$ from bregma) for signal analysis; (2) a monopolar electrode placed over the cerebellum (reference electrode); and (3) a bipolar electrode inserted into the injected hippocampus. The electrodes were made of stainless-steel wire isolated by polyester (diameter, $0.125 \mathrm{~mm}$; FE245840; Goodfellow). They were inserted in the skull above the cortex and the cerebellum. The bipolar electrode was formed of two twisted polyester insulated stainless-steel wires. It was aimed at the right hippocampus with the same coordinates as for the injection site.

For recordings or stimulations within the $\mathrm{PF}$, mice were implanted bilaterally with bipolar electrodes (AP, -2.3 ; ML, \pm 0.6 ; DV,$-3.7 \mathrm{~mm}$ from bregma). For local drug applications, they were implanted with stainless-steel injection guide cannulae (o.d., $0.40 \mathrm{~mm}$; inner diameter, $0.3 \mathrm{~mm}$; Phymep; AP, -2.3 ; ML, \pm 0.6 ; DV,$-2.6 \mathrm{~mm}$ from bregma). These guide cannulae were positioned $1.1 \mathrm{~mm}$ above the target areas. Stainless-steel stylets (o.d., $0.27 \mathrm{~mm}$; Cortat) were inserted into the guide cannulae to keep their patency. All of the electrodes were soldered to a female microconnector (BLR150Z; Fischer Elektronik) fixed to the skull by cyanolytic glue and dental acrylic cement. Animals were allowed a week for recovery after surgery.

In vivo extracellular and intracellular recording experiments. Extracellular (single-unit) and intracellular recordings were performed in vivo from 10 adult (12-16 weeks old) C57BL/6 male mice, 4 weeks after they received an intrahippocampal injection of KA. Animals were initially anesthetized with chloral hydrate ( $4 \%$ chloral hydrate in $9 \% \mathrm{NaCl} ; 10$ $\mathrm{ml} / \mathrm{kg}$, i.p.). A cannula was then inserted into the trachea, and the animal was placed in a stereotaxic frame. Wounds and pressure points were repeatedly (every $2 \mathrm{~h}$ ) infiltrated with lidocaine (2\%). Once the surgical procedures had been completed (see below), mice were maintained in a narcotized and sedated state by injections of fentanyl $\left(3 \mu \mathrm{g} \cdot \mathrm{kg}^{-1}\right.$, i.p.; Janssen-Cilag) and haloperidol $\left(600 \mu \mathrm{g} \cdot \mathrm{kg}^{-1}\right.$, i.p.; Janssen-Cilag) repeated every 20-30 min (Charpier et al. 1999; Slaght et al., 2002). To obtain long-lasting stable intracellular recordings, mice were immobilized with D-tubocurarine ( $0.2 \mathrm{mg}$, i.p., every hour; Sigma) and artificially ventilated. The degree of anesthesia was assessed by continuously monitoring the LFPs and heart rate, and additional doses of fentanyl, haloperidol, and D-tubocurarine were administrated at the slightest change toward an awaked pattern. Body temperature was maintained (36.5$37.5^{\circ} \mathrm{C}$ ) with a homeothermic blanket. At the end of the experiments, animals received an overdose of sodium pentobarbital $(60 \mathrm{mg} / \mathrm{kg}$, i.p.; Dolethal; Centravet).

Electrophysiological recordings and analysis. For standard LFP recordings, animals were placed in Plexiglas boxes $(14 \times 14 \times 24.5 \mathrm{~cm})$ for habituation at least $1 \mathrm{~h}$ before recordings. LFPs were recorded in awake freely moving animals using a digital acquisition system (Coherence 3NT; Deltamed) with a sampling rate of $256 \mathrm{~Hz}$ and analog bandpass filtering between 1 and $90 \mathrm{~Hz}$. Each animal was recorded at regular intervals (three times/week) for 1 month after KA injection to monitor the progressive development of HPDs (i.e., epileptogenesis) and their stabilization and recurrence (i.e., chronic phase) as described previously (Riban et al., 2002). Only animals showing reproducible and recurrent HPDs were used in this study.

For the quantification of seizure reproducibility, the number, mean, and cumulative duration of hippocampal discharges were measured every week during three 20 min periods and then averaged. For local drug applications, the number, mean, and cumulative duration of hippocampal discharges were measured during three and six 20 min periods before and after local drug application, respectively. For PF electrical stimulation experiments, animals were recorded for $1 \mathrm{~h}$ before the stimulation sessions. During the recording and stimulation sessions, the mice were continuously watched to detect changes in their behavior.

Mice were directly connected to a miniature headstage preamplifier (MPA8I; Multi Channel Systems), and signals were amplified, filtered (2000×, bandpass $1 \mathrm{~Hz}$ to $5 \mathrm{kHz}$; FA32I; Multi Channel Systems), and stored to hard disk (16 bit analog-to-digital converter; $2 \mathrm{kHz}$ sampling frequency; CED Power1401; Cambridge Electronic Design) using the Spike2 software.

Time-frequency analysis of 36 HPDs and concomitant right PF and sensorimotor cortex activity collected in six freely moving mice was performed using an in-house developed toolbox for dynamical analysis of intracerebral LFP. The amplitude (square root of power) of oscillatory activity between 1 and $60 \mathrm{~Hz}$ was obtained using standard time-frequency analysis based on the Morlet wavelet transform (Le Van Quyen et al., 2001). The first and last spikes of each discharge were used to define its onset and termination, respectively. The time window of analysis of each discharge was defined to contain $6 \mathrm{~s}$ before HPDs onset and after HPDs termination. For each frequency, the amplitude was computed on seven periods length sliding time window, providing an effective frequency-specific time resolution. Time-frequency sampling of the time-frequency plane was $50 \mathrm{~ms} / 1 \mathrm{~Hz}$. Time-frequency data were normalized using the standard procedure: for each frequency, the mean of the baseline was subtracted to the data and then demeaned data were divided by the standard deviation of the baseline. Baseline was defined as the $4 \mathrm{~s}$ preceding each HPD. Finally, the typical time-frequency pattern of recorded HPDs was defined as the median value over HPDs of the normalized time-frequency charts computed as such. Before median averaging, time-frequency charts were resampled linearly on an arbitrary time scale to normalize HPD duration.

Neurons from the hippocampus, presumably located within the CA1 region, were recorded within $1 \mathrm{~mm}$ of the LFP electrode at the following coordinates: $2.3 \mathrm{~mm}$ posterior to the bregma, $0.6 \mathrm{~mm}$ lateral to the midline, and 1.5-2 mm under the cortical surface. Intracellular and extracellular recordings of thalamic neurons were made from the same region of the PF nucleus ipsilateral to the injected hippocampus at the following stereotaxic coordinates: $2.3 \mathrm{~mm}$ posterior to the bregma, $0.6 \mathrm{~mm}$ lateral to the midline, and $2.75-3.75 \mathrm{~mm}$ ventral to the brain surface. The re- 
corded thalamic cells were subsequently confirmed as PF neurons after examination of their morphology and their localization (see below). In all experiments, the intracellular or single-unit extracellular recordings were simultaneously performed with the corresponding ipsilateral hippocampal LFP.

Intracellular recordings were obtained with glass micropipettes filled with $2 \mathrm{M}$ potassium acetate $(50-70 \mathrm{M} \Omega$ ), and the reference electrode was placed in a muscle at the opposite side of the head. For single-unit extracellular recordings and juxtacellular labeling (see below), glass electrodes were filled with $0.5 \mathrm{M} \mathrm{NaCl}$ and $1.7 \%$ neurobiotin (10-20 M $\Omega$; Vector Laboratories).

Intracellular recordings were obtained under current-clamp conditions using the active bridge mode of an Axoclamp-2B amplifier (Molecular Devices). Data were digitized with a sampling rate of $10 \mathrm{kHz}$ (intracellular and extracellular signals) or $1 \mathrm{kHz}$ (LFP) for off-line analysis. Measurements of apparent membrane input resistance and time constant were based on the linear electrical cable theory applied to an idealized isopotential neuron (Rall, 1969). Membrane input resistance was assessed by measurement of the mean $(n \geq 10)$ membrane potential change at the end of hyperpolarizing current pulses of $-0.4 \mathrm{nA}(200 \mathrm{~ms}$ duration, applied every $1.25 \mathrm{~s}$ ), and the membrane time constant was the time taken for the membrane potential to reach $63 \%$ of its final value. Average membrane potential of hippocampal and thalamic neurons was determined from the average membrane potential of all interictal periods. When a tip potential was recorded after termination of the intracellular recording, the membrane potential values were corrected accordingly. The amplitude of action potentials was calculated as the potential difference between their voltage threshold, measured as the membrane potential at which the $d V / d t$ exceeded $10 \mathrm{~V} \mathrm{~s}^{-1}$ (Mahon et al., 2003), and the peak of the spike waveform. Numerical values are given as means $\pm \mathrm{SD}$ unless stated otherwise.

Cumulative histograms of the binned action potential discharge of extracellularly recorded neurons were performed by first encoding in time the position of the peak of LFP spikes and action potentials in two separate channels using the memory buffer function and then using the "stimulus histogram" function of the Spike 2 software (CED Software; Cambridge Electronic Design).

Morphological identification of recorded PF neurons. Extracellularly recorded neurons were labeled by juxtacellular injection of neurobiotin (Pinault, 1996). Briefly, positive current pulses (1-8 nA; $200 \mathrm{~ms}$ ) were applied at a frequency of $2.5 \mathrm{~Hz}$ through the bridge circuit of the amplifier. The current was slowly increased while the electrode was advanced toward the neuron in $1 \mu \mathrm{m}$ steps (LSS-1000 Inchworm motor positioning system; Burleigh Instruments) until the cell discharge was driven by the injected current. Current pulses were applied for a 10-30 min period to obtain a reliable labeling of neuronal processes. At $1-2 \mathrm{~h}$ after the injection, the animal received a lethal dose of pentobarbital and was perfused via the ascending aorta with $200 \mathrm{ml}$ of $0.3 \%$ glutaraldehyde and $4 \%$ paraformaldehyde in phosphate buffer $(\mathrm{PB}), 0.1 \mathrm{M}, \mathrm{pH}$ 7.4. Brains were postfixed for $2 \mathrm{~h}$ in the same fixative solution without glutaraldehyde and then immersed in $30 \%$ sucrose $\mathrm{PB}$ at $4^{\circ} \mathrm{C}$ until sectioning. Frozen sections of fixed brains were cut at $50-70 \mu \mathrm{m}$ in the frontal plane and serially collected in PB. After several rinses in PB, neurobiotin was revealed by incubation of the sections in the avidin-biotin peroxidase complex (1:100; Vector Laboratories) in PB containing $0.3 \%$ Triton $\mathrm{X}-100$ for at least $12 \mathrm{~h}$ at $4^{\circ} \mathrm{C}$. Incubated sections where washed in $\mathrm{PB}$ (two times for $10 \mathrm{~min}$ ) before immersion in a solution containing $0.005 \%$ 3,3'-diaminobenzidine tetrahydrochloride (Sigma), 0.4\% nickel-ammonium sulfate, and $0.0006 \% \mathrm{H}_{2} \mathrm{O}_{2}$. After several washes in $\mathrm{PB}$, sections were mounted on gelatin-coated slides, counterstained with safarin, and dehydrated through alcohol to xylene for light microscopic examination. The location of labeled neurons within the PF thalamic nucleus was confirmed using the atlas of Paxinos and Franklin (2001).

Intracerebral electrical stimulations. All stimulations were performed with a Grass S88H stimulator (Grass Technologies) delivering square current pulses of constant current. Before starting each stimulation session, a period of $1 \mathrm{~h}$ was allowed for habituation of the animals to the test cage. Thereafter, the animals, equipped with bipolar intra-PF electrodes, received a $5 \mathrm{~s}$ electrical stimulation applied within the first $2 \mathrm{~s}$ of an HPD onset. The parameters used (frequency, $130 \mathrm{~Hz}$; monophasic mode, pulse width, $60 \mu \mathrm{s}$ ) were determined according to previous stimulation studies of other structures (e.g., SNr, subthalamic nucleus) showing suppressive effects on epileptic seizures (Vercueil et al., 1998; Velísek et al., 2002; Deransart and Depaulis, 2004; Feddersen et al., 2007). Additional trials were made with $20 \mathrm{~Hz}$ stimulations. The stimulation intensity was progressively increased from 5 to $150 \mu \mathrm{A}$ by $5 \mu \mathrm{A}$ steps, with at least a 1 min interval between two stimulations, until the observation of (1) HPD interruption, defined as the return to baseline of hippocampus activity within $2 \mathrm{~s}$ after stimulation onset for at least $15 \mathrm{~s}$ (antiepileptic threshold), (2) antiepileptic threshold associated with a slight head and/or trunk straightening without paw repositioning (behavioral threshold), or (3) behavioral threshold associated with paw repositioning and/or clonus of the limbs or contralateral whole body turning around the axis (motor threshold) (Deransart and Depaulis, 2004). These changes in behavior were measured by continuous observation of the animal by the experimenter. Such thresholds were determined for different modes of stimulation (referential vs bipolar; unilateral vs bilateral).

Intraparafascicular drug applications. D-(E)-2-amino-4-methyl-5-phosphono-3-pentanoic acid (CGP40116; Ciba Geigy), NMDA (Sigma), muscimol (5-aminomethyl-3-hydroxyisoxazole; Sigma), and picrotoxin (Sigma) were dissolved in $\mathrm{NaCl} 0.9 \%$, aliquoted, and kept frozen at $-80^{\circ} \mathrm{C}$.

After a 60 min reference period of LFPs recording, animals were gently handled and received within 1 min a bilateral injection of (1) 2 or 4 pmol (10 or $20 \mu \mathrm{M}$ ) of CGP40116, a competitive inhibitor of NMDA glutamatergic receptors; (2) 17.5 or 35 pmol of muscimol, a $\mathrm{GABA}_{\mathrm{A}}$ receptors agonist; (3) 5 or 10 pmol of NMDA, the glutamatergic NMDA receptors

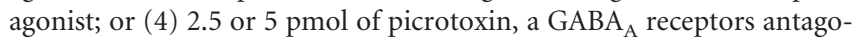
nist, in a volume of $200 \mathrm{nl}$ per side. These compounds and the doses used were determined according to previous studies in other animal models of epilepsy (Deransart et al., 1996, 1998, 1999; Nail-Boucherie et al., 2005). Since HPD generally occurs when animals are in a state of quiet wakefulness, we used only low doses of drugs to avoid behavioral side effects, like awakening, that may have artificially decreased the occurrence of HPDs. Injection cannulae (o.d., $0.28 \mathrm{~mm}$ ) were connected to a $10 \mu$ l Hamilton microsyringe moved by a micropump (CMA/100; Carnegie Medicin). Each animal received the drug and the vehicle $(\mathrm{NaCl} 0.9 \%)$ according to a Latin-square design with at least $48 \mathrm{~h}$ between two injections. Each mouse was thus used as its own control and was injected a maximum of four times. LFP activity was then recorded for $120 \mathrm{~min}$. The animals were continuously watched to detect any behavioral effects induced by the drug injection.

Effects of pharmacological injections on spontaneous LFPs recorded in the cortex and hippocampus were evaluated with the amplitude spectrum of the fast Fourier transform computed on $6 \mathrm{~s}$ time windows of interictal activity taken every $20 \mathrm{~min}$ before and after injection.

Histology. After completion of each freely moving experiment, the animals were killed with an overdose of pentobarbital $(60 \mathrm{mg} / \mathrm{kg}$, i.p.; Dolethal; Centravet) and their brains were removed, frozen, and cut in 20 $\mu \mathrm{m}$ coronal sections. These sections were stained with cresyl violet and each recording, stimulation, or injection site was localized with reference to the atlas of Paxinos and Franklin (2001). Only data from animals with (1) correct location of the hippocampal electrode, (2) correct histological feature in the injected hippocampus (Riban et al., 2002), and (3) injection or stimulation sites located within the boundaries of the PF were kept in statistical analyses.

Statistics. For the follow-up of HPD stability, data were expressed as mean \pm SEM of cumulative duration, mean duration, and number of HPDs per 20 min period. The data collected at different weeks after KA injection were compared using a nonparametric ANOVA for related samples (Friedman test). Paired comparisons between two time points were done using a nonparametric test for related samples (Wilcoxon test) (Siegel, 1956).

For deep brain stimulation experiments, thresholds were expressed as mean \pm SEM and were compared using the nonparametric tests of Kruskal-Wallis and Mann-Whitney when independent groups were concerned (localization study, comparisons between modes of stimulation) or the nonparametric tests of Friedman and Wilcoxon for related 
samples (comparisons between parameters of stimulations, comparison between periods).

For local drug application experiments, data were expressed as mean \pm SEM of percentage of cumulative duration, mean duration, and number of HPDs per 20 min period, compared with vehicle condition $(\mathrm{NaCl}, 100 \%)$. Within each period, the means between test conditions were compared using a nonparametric ANOVA (Friedman test). Then, paired comparisons versus control conditions (vehicle only) were performed using a nonparametric test for related samples (Wilcoxon test).

Statistical analysis was performed with SigmaStat 3.0 (SPSS). The significance level for all statistical analysis was set at $p<0.05$.

\section{Results}

Correlated changes in hippocampus, $\mathrm{PF}$ nucleus, and sensorimotor cortex local field potentials during hippocampal paroxysmal discharges

Recurrent HPDs (Fig. $1 A$ ) were observed in the ipsilateral hippocampus 2 weeks after KA injection and were recorded thereafter during the 6 week duration of the study. These discharges generally occurred at rest and were associated with behavioral arrest and/or mild facial automatisms as described previously (Riban et al., 2002; Heinrich et al., 2006; Meier et al., 2007). In between HPDs, isolated spikes or bursts of three to four spikes were observed in the hippocampus. Only occasionally, a propagation of the paroxystic activity to the cerebral cortex, leading to a generalized clonic seizure, was recorded. The stability of HPD was first assessed in nine mice from 2 to 7 weeks after KA injection using the mean and $\mathrm{cu}-$ mulated duration as well as the number of HPDs by 20 min periods. These variables were found very stable over the 6 weeks, with no significant statistical differences (Table 1).

We performed time-frequency power analysis (Fig. 1) of LFPs recorded in the hippocampus, PF nucleus, and sensorimotor cortex of freely moving mice displaying established recurrent HPD $(n=$ 36 HPDs from 6 mice; $28 \pm 5 \mathrm{~d}$ after KA injection) (Fig. 1A). Oscillatory hippocampal activities were mostly below $40 \mathrm{~Hz}$ (Fig. $1 B$ ) with two distinct time-dependent behaviors: (1) hippocampal LFP power drastically increased in the $2-10 \mathrm{~Hz}$ frequency band at the beginning of the HPD and then progressively decreased, and (2) a weaker increase of power was also observed between 20 and $40 \mathrm{~Hz}$, which was maintained throughout the HPD (Fig. $1 B$ top left map, $C$ ). In the PF $(n=36$ HPDs from 6 mice) and the sensorimotor cortex $(n=28$ HPDs from 3 mice), a progressive increase of synchronous oscillatory activity was detected between 5 and $20 \mathrm{~Hz}$ (Fig. 1 B, C). The power averaged in this frequency band reached its maximum value in the PF just after termination of the HPD (Fig. 1C). This increase of synchronous oscillatory activity was then further analyzed

A

Start
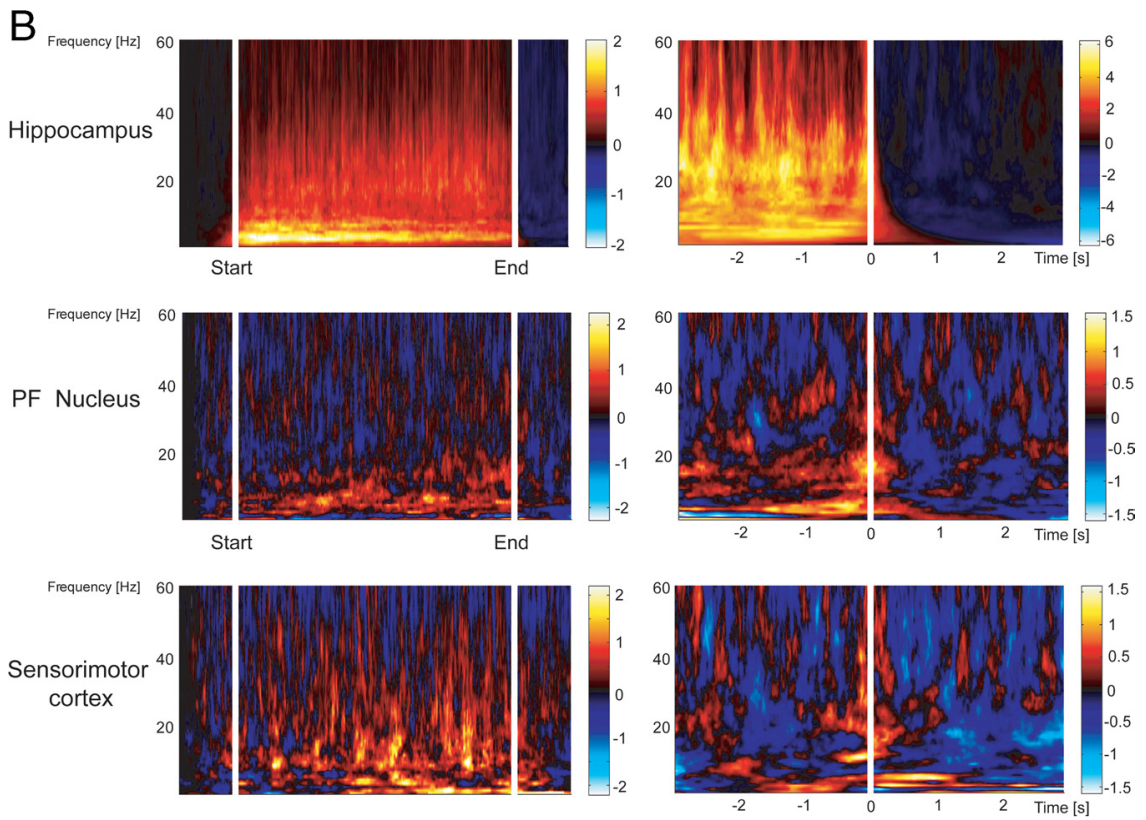

End End

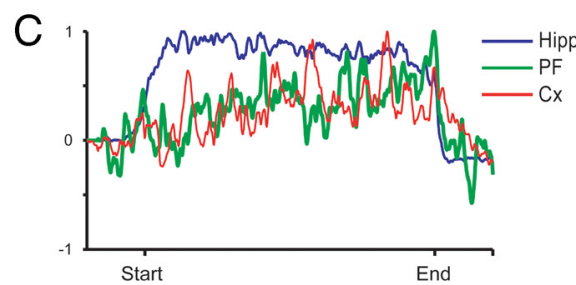

Figure 1. Parafascicular and sensorimotor cortex local field potential activities during HPDs. $A$, Simultaneous LFP recording of the activity of the hippocampus (top), PF (middle), and sensimotor cortex (bottom) during a spontaneous HPD occurring in a freely moving mouse. $\boldsymbol{B}$, Left, Median average over seizures of LFP power in the time-frequency plane ( $n=36$ intra-PF and hippocampa normalizing the time axis of the time-frequency representation before median averaging (correspondence of start and end of

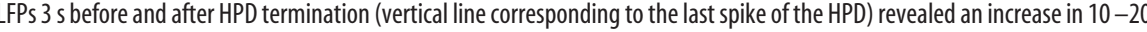
Hz synchronous oscillatory activity of the PF nucleus and sensorimotor cortex within the second before HPD termination. The color blue), parafascicular (green), and cortical (Cx; red) LFPs. Note the progressive increase in time of the PF LFP power leading to a maximum at the HPD termination.

(Fig. $1 B$, right maps), and a transient increase in the $10-20 \mathrm{~Hz}$ band was found to occur during the last second of the HPD. Such dynamic changes in LFP activity were not observed in the hippocampus.

These data show that although no paroxysmal-like activity was found in the PF during HPD, the specific electrical changes observed in this structure suggests a functional link between PF and hippocampus during HPD.

\section{Intracellular activities of hippocampal neurons during spontaneous HPD in vivo}

To further understand the relationships between hippocampal and PF neuronal activity, we determined the neuronal substrate of HPD by simultaneously recording hippocampal LFPs and in- 


\begin{tabular}{lcccccc}
\hline & \multicolumn{5}{l}{ Time after KA injection (weeks) } & \multicolumn{3}{c}{} \\
\cline { 2 - 6 } & 2 & 3 & 4 & $19 \pm 1$ & 6 \\
\hline Number of HPDs & $24 \pm 2$ & $21 \pm 2$ & $22 \pm 2$ & $21 \pm 1$ & $19 \pm 1$ \\
Cumulated duration of HPDs (s) & $407 \pm 43$ & $347 \pm 40$ & $325 \pm 27$ & $349 \pm 28$ & $369 \pm 26$ \\
Mean duration of HPDs (s) & $17 \pm 1$ & $16 \pm 2$ & $17 \pm 1$ & $19 \pm 1$ & $18 \pm 1$ & $21 \pm 2$ \\
\hline
\end{tabular}

Averaged number of, cumulated, and mean durations by 20 min periods of HPD recorded in nine mice from 2 to 7 weeks after KA injection.

A

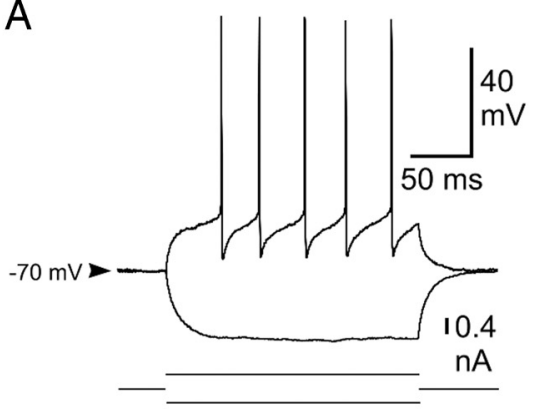

B1

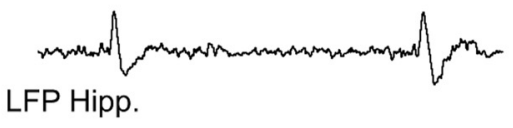

C

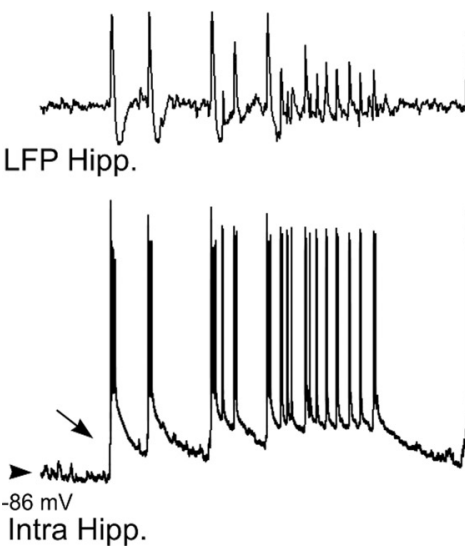

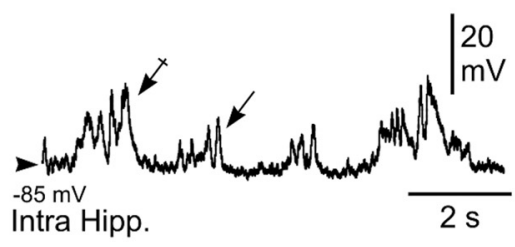

Intra Hipp.
B2

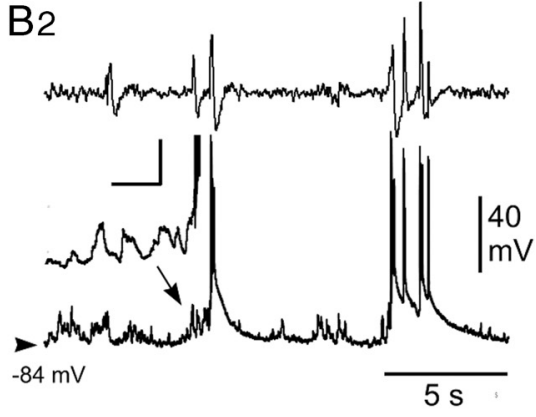

D
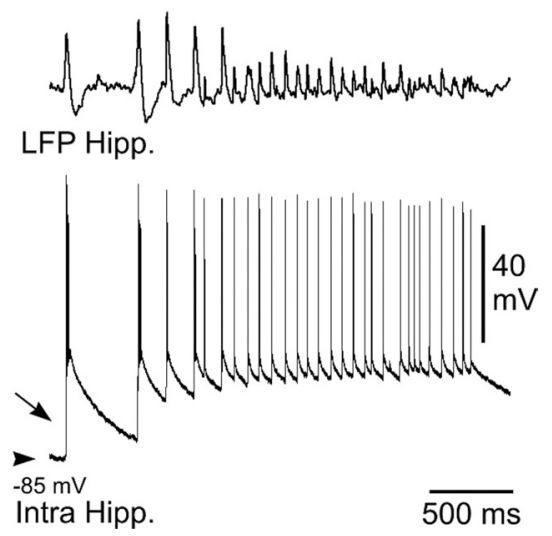

Figure 2. Intracellular activity of hippocampal neurons from the KA-injected mouse in vivo. $A$, Voltage responses (top traces) of a neuron located in the CA1 region of the epileptic hippocampus to hyperpolarizing (average of 5 successive trials) and depolarizing (single-response) current pulses (bottom traces). $\boldsymbol{B}$, Intracellular correlate (bottom traces) of LFP (top traces) interictal-like activities. $\boldsymbol{B}_{\boldsymbol{1}}$, Subthreshold events. In between the interictal spikes, the hippocampal (Hipp.) neuron displayed bursts of dPSPs (arrow), which were amplified (crossed arrow) when coincident with paroxysmal LFP. $\boldsymbol{B}_{2}$, Suprathreshold events. Brief clusters of LFP spikes could be correlated with neuronal bursting, which were generated by large-amplitude depolarization gradually constructed by temporal summation of excitatory synaptic events (inset; calibration: $30 \mathrm{mV}, 20 \mathrm{~ms}$ ). C, D, Intracellular activity (bottom trace) of pyramidal neurons associated with LFP seizure activity (top trace). Note the abrupt depolarization at the onset of seizure (arrows) and the sustained neuronal depolarization throughout the local paroxysm. The inset in $\boldsymbol{C}$, is the enlargement of the initial neuronal paroxysmal shift indicated by the arrow. Arrowheads indicate the mean interictal membrane potential. Records shown in $\boldsymbol{A}-\boldsymbol{C}$ and $\boldsymbol{D}$ are from two separate experiments.

tracellular activities. Recorded hippocampal neurons were located in the CA1 region of the epileptic hippocampus in the vicinity $(1 \mathrm{~mm})$ of the KA injection site. These neurons had electrical membrane properties and intrinsic firing patterns similar to those described previously from CA1 pyramidal neurons recorded from normal rats in vivo (Henze and Buzsáki, 2001) and KA-treated mice in vitro (Le Duigou et al. 2008). Their action potential had an amplitude of $63.5 \pm 4.5 \mathrm{mV}$ ( $n=8$ cells), a duration of $1.3 \pm 0.5 \mathrm{~ms}$ ( $n=8$ cells $)$, and a voltage threshold of $-51.6 \pm 7.1 \mathrm{mV}(n=8$ cells $)$, and was followed by a highamplitude afterhyperpolarization $(10.6 \pm 7.4 \mathrm{mV} ; n=8$ cells $)$ (Fig. $2 A$ ). Membrane input resistance and membrane time constant were $31.1 \pm 14.8 \mathrm{M} \Omega$ and $3.9 \pm 2.4 \mathrm{~ms}$, respectively $(n=8$ cells) (Fig. $2 A$ ). In response to injection of suprathreshold current pulses, hippocampal cells discharged repetitively with a tonic and regular firing pattern (Fig. $2 \mathrm{~A}$ ).

In absence of paroxysmal activity in the corresponding LFP, hippocampal neurons were highly polarized, with a mean mem- brane potential of $-78.1 \pm 9.6 \mathrm{mV}(n=8$ cells $)$, and displayed small-amplitude bursts of depolarizing postsynaptic potentials (dPSPs) that remained, in the vast majority of the cells (seven of eight), subthreshold for action potential generation (Fig. $2 B_{1}$, arrow). The remaining neuron showed a moderate background spontaneous firing of $1.76 \mathrm{~Hz}$.

The occurrence of interictal-like activities, which consisted of single or short clusters (two to five paroxysmal events) of highvoltage sharp waves as described previously (Riban et al., 2002), was coincident in hippocampal cells with an increase in both duration and amplitude of the grouped dPSPs (Fig. $2 B_{1}$, crossed arrow). A progressive temporal summation (lasting 0.5-1 s) of these interictal excitatory synaptic events (Fig. $2 B_{2}$, arrow) could eventually lead to a sustained depolarization (up to $33.7 \pm 9.2$ $\mathrm{mV} ; n=126$ interictal events from 8 cells) generating bursts of action potentials ( $13.4 \pm 5.3$ action potentials; $n=126$ interictal events from 8 cells) (Fig. $2 B_{2}$ ). These paroxysmal depolarizing shifts slowly decayed within $3.3 \pm 1.5 \mathrm{~s}(n=126$ interictal events, 8 cells $)$. 
HPDs were characterized in the LFP by the repetition of high-voltage biphasic sharp waves $(44.0 \pm 14.4$ waves; $n=58$ HPDs from 8 cells) (Fig. 2C,D) lasting $16.9 \pm 7.6 \mathrm{~s}$ and having an interval frequency $(2.9 \pm 1.3 \mathrm{~Hz})$ similar to that calculated from behaving KA-treated mice (see Table 1). Contrasting with the interictal discharges, the start of HPDs was concomitant with an abrupt (Fig. $2 C$, inset) and large (33.6 $\pm 8.2 \mathrm{mV} ; n=58$ HPDs from 8 cells) depolarization, arising from a relatively quiescent membrane potential and causing a burst of action potentials (Fig. 2C,D). This initial ictal neuronal event was followed by a sustained membrane depolarization of $19.2 \pm 6.9 \mathrm{mV}(n=58$ HPDs from 8 cells), which was maintained throughout the HPDs (Fig. 2C,D). This prolonged depolarization was mostly crowned by repeated sharp depolarizing potentials, which occurred from the decay phase of the preceding one and generated a cluster of action potentials $(4.0 \pm 1.8$ action potentials; $n=58$ epileptic HPDs from 8 cells). At the end of the HPDs, hippocampal neurons slowly repolarized, within $6.3 \pm$ $3.6 \mathrm{~s}$ ( $n=58$ HPDs from 8 cells), toward their interictal membrane potential.

These findings provide, to our knowledge, the first in vivo intracellular description of the interictal and ictal events occurring in the hippocampus of a mouse model of MTLE.

\section{Intracellular activity of PF neurons during HPD}

To investigate the functional coupling between hippocampus and thalamic PF nucleus during HPD, we performed in vivo intracellular recordings of PF neurons simultaneously with LFP activities in the ipsilateral CA1 region. The five recorded neurons, from five different mice, had an average membrane resistance of $29.7 \pm 9.3 \mathrm{M} \Omega$ and a membrane time constant of $10.5 \pm 3.7 \mathrm{~ms}$ (Fig. $3 A$ ). Their action potentials had an amplitude of $58.1 \pm 6.8$ $\mathrm{mV}$ and a duration of $0.9 \pm 0.3 \mathrm{~ms}$, and were followed by an afterhyperpolarization of large amplitude $(9.2 \pm 4.4 \mathrm{mV})$ (Fig. $3 A)$. When applied from the resting potential, suprathreshold current pulses elicited sustained tonic firing (Fig. $3 A_{1}$ ). Moreover, the injection of negative current pulses was immediately followed by a postanodal excitation, likely caused by a lowthreshold calcium potential (Fig. $3 A_{2}$, top) generating a burst of action potentials (Fig. $3 A_{1}, A_{2}$ ), and/or induced a sag potential (Fig. $3 A_{2}$, bottom), likely caused by a hyperpolarization-activated inward cationic current. Altogether, these electrical membrane properties were consistent with those classically described in thalamocortical cells (Jahnsen and Llinás, 1984).

During interictal periods, the intracellular activity of PF neurons was characterized by a sustained barrage of highfrequency, small-amplitude, depolarizing synaptic potentials corresponding to a mean membrane potential of $-58.5 \pm 3.8$ $\mathrm{mV}(n=161$ interictal periods from 5 neurons $)$. This back-

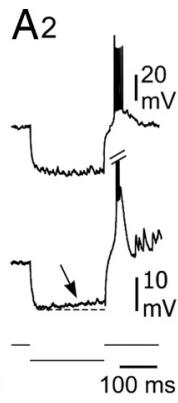

B

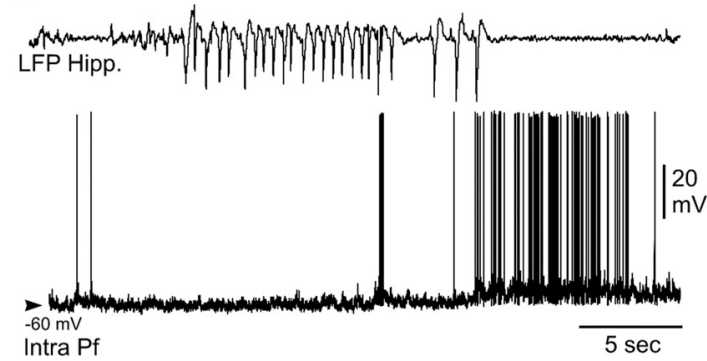

D

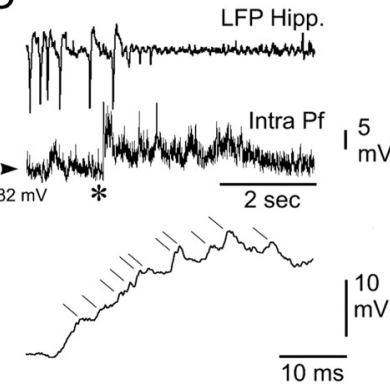

Figure 3. Intracellular activity of PF thalamic neurons is disrupted by hippocampal seizures in vivo. $\boldsymbol{A}$, Electrophysiological properties of recorded PF thalamic neurons. $\boldsymbol{A}_{1}$, Voltage responses (top traces) of a PF thalamic neuron to hyperpolarizing (average potentialfrom 10 successive trials) and depolarizing (single-response) current pulses (bottom traces). Note the tonic firing induced of action potentials promptly followed the HPD. $C$, In this other neuron, the firing rate was decreased during the HPD and then

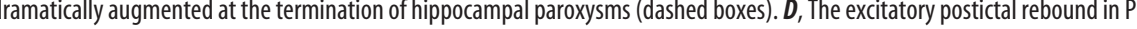
segment (bottom) indicated by the asterisk, the excitatory rebound resulted from the temporal summation of individual dPSPs (oblique lines). Arrowheads indicate the mean interictal membrane potential.

ground synaptic activity caused an irregular discharge of action potentials, with a mean frequency of $7.9 \pm 7.0 \mathrm{~Hz}(n=5$ neurons) (Fig. $3 B, C$ ).

The intracellular activity of PF neurons $(n=3)$ was clearly affected by the occurrence of HPDs. The onset of hippocampal paroxysms was correlated with a slight hyperpolarization of PF neurons $(-1.1 \pm 0.5 \mathrm{mV} ; n=27$ from three cells $)$ and a transient decrease in the mean firing rate by $30.5 \pm 10.5 \%(n=27$ from three cells) (Fig. $3 B, C$ ), which could lead to a complete interruption in cell discharge. A striking finding was the robust increase in PF neurons firing that coincided with the termination of HPDs (Fig. $3 B, C$ ). This sustained excitation had a duration of $3.0 \pm$ $1.8 \mathrm{~s}(n=27$ from three cells) and resulted in a mean firing rate of $17.7 \pm 9.5 \mathrm{~Hz}$ (Fig. 3 B, C). Similar exacerbated activities in PF neurons could be also observed immediately after interictal discharges in the hippocampal LFPs (result not shown). Continuous injection of negative DC currents ( $n=3$ cells, three animals) revealed that these discharges in PF neurons at the end of the seizure were attributable to a sustained membrane depolarization sculpted by the temporal summation of high-frequency dPSPs (Fig. 3D).

These data confirm and extend the correlated changes found in the thalamic LFPs as a function of the different phases of the HPDs, and further indicate a mirror-like firing activity in hippocampal and thalamic cells. 

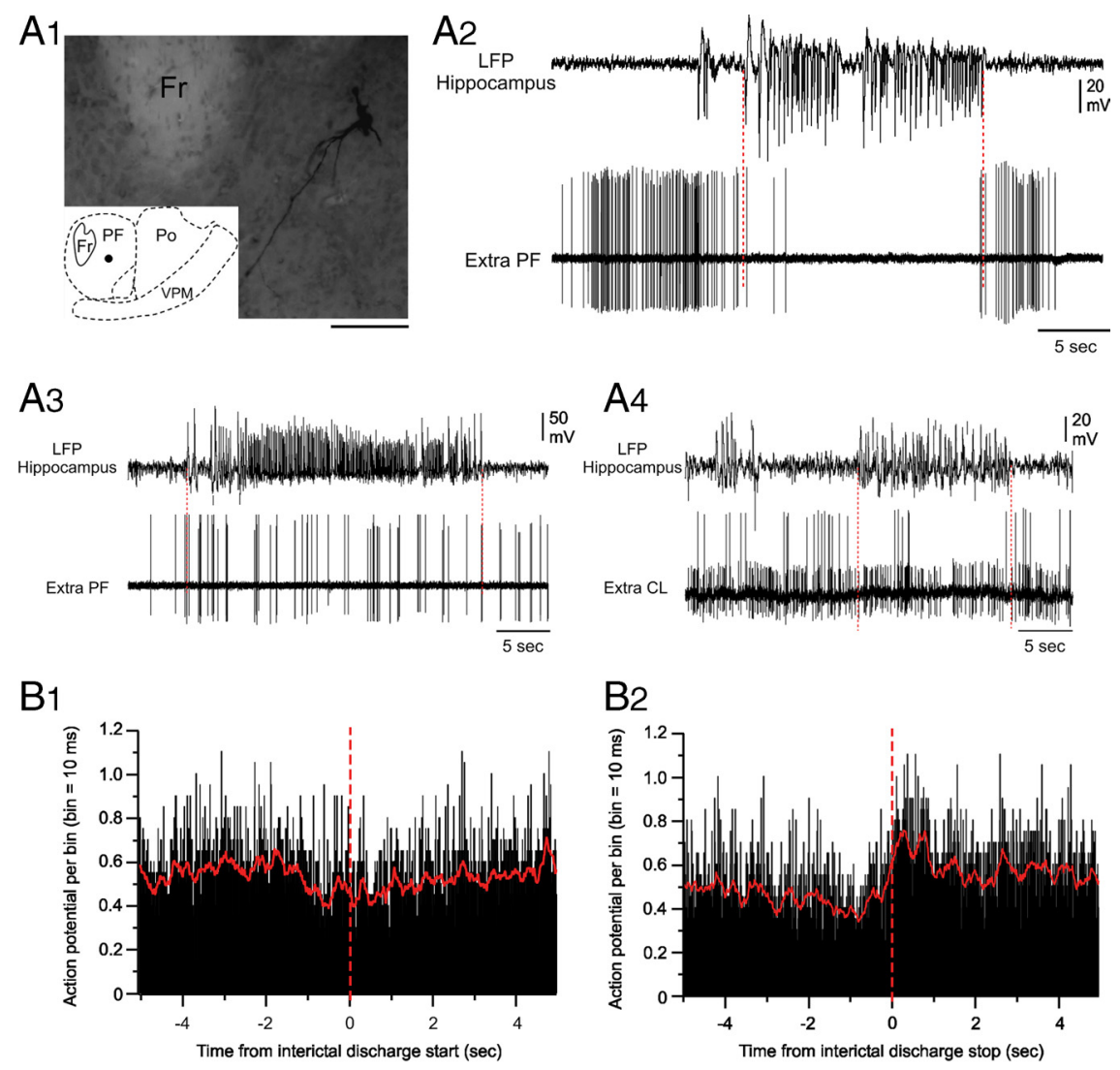

B3
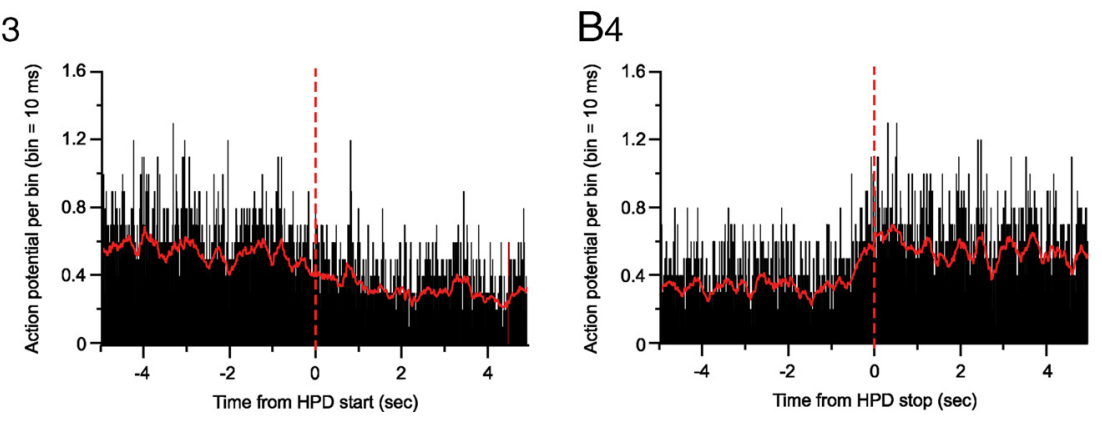

Figure 4. Extracellular recordings from PF neurons during HPDs. $A_{1}$, Microphotograph of a PF neuron labeled by juxtacellular injection of neurobiotin. The cell body (filled circle in the inset, schematic coronal plane drawing) was located in the central region of the lateral part of the PF nucleus. Anteriority from the interaural line was $1.62 \mathrm{~mm}$. Fr, Fasciculus retroflexus; Po, posterior thalamic nucleus; VPM, ventral posteromedial thalamic nucleus. Scale bar, $100 \mu \mathrm{m} . A_{2}-A_{4}$, Single-spike activity of thalamic neurons (bottom traces) during paroxysmal activity in the ipsilateral hippocampus (top traces). $A_{2}$, Disruption of the spontaneous extracellular activity of the PF neuron shown in $A_{1}$ during the HPD (between the dashed vertical lines) and representative of the first subpopulation of PF cells. $A_{3}$, Extracellular activity of another $\mathrm{PF}$ neuron affected by the HPD occurrence and representative of the second subpopulation of PF cells. No change in their firing rate was observed. $A_{4}$ S Simultaneous recording of two centrolateral thalamic nucleus $(\mathrm{CL})$ neurons during HPD. Note that the activity of these two cells is not affected by the HPD. $\boldsymbol{B}_{1}-\boldsymbol{B}_{4}$, Mean cumulative histograms of binned action potential discharge of $19 \mathrm{PF}$ neurons aligned to hippocampal epileptic events ( $5 \mathrm{~s}$ before and after the start of short clusters of isolated spikes $\left(\boldsymbol{B}_{1}, \boldsymbol{B}_{3}\right)$ and HPDs $\left(\boldsymbol{B}_{2}, \boldsymbol{B}_{4}\right)$. Note slight decrease of the activity of PF neurons after the beginning of hippocampal clusters of isolated spikes $\left(\boldsymbol{B}_{7}\right)$ or $\operatorname{HPDs}\left(\boldsymbol{B}_{3}\right)$. Contrarily, the mean firing rate of PF neurons increased 500 ms before the end of cluster of isolated spikes $\left(\boldsymbol{B}_{2}\right)$ and $\mathrm{HPDs}\left(\boldsymbol{B}_{4}\right)$ and lasted approximately $1.5 \mathrm{~s}$ after the end of hippocampal paroxysms.

\section{Extracellular activity of PF neurons during HPDs}

To further extend the statistical analysis of the functional relationships between hippocampus and PF nucleus during HPDs, we then recorded the spontaneous activity of PF neurons in KAtreated mice by extracellular recordings of 30 single units from seven mice. Recorded cells, which were morphologically identified by juxtacellular injection of neurobiotin (see Materials and Methods), were located within the PF nucleus (Fig. $4 A_{1}$ ). We could discriminate two populations of PF cells according to their distinctive patterns of electrical activity which were affected, or not, by the occurrence of HPDs. However, all PF neurons showed an arrhythmic spontaneous spike activity $(2.9 \pm 0.53 \mathrm{~Hz})$ during the interictal periods (Fig. $4 A_{2}, A_{3}$ ).

The first subpopulation of PF cells (Fig. $\left.4 A_{2}\right)(n=19)$, the activity of which was changed during HPDs, had a mean firing frequency during interictal periods of $3.04 \pm 0.77 \mathrm{~Hz}$ (from 0.1 to $9.48 \mathrm{~Hz}$ ). During interictal clusters of isolated spikes (interictal discharges) (Fig. $4 B_{1}, B_{2}$ ) and HPDs (Fig. $4 B_{3}, B_{4}$ ), the firing rate of this set of thalamic neurons decreased, reaching the mean values of $2.4 \pm 0.6 \mathrm{~Hz}$ (range, $0-4.89 \mathrm{~Hz} ; n=375$ interictal clusters of isolated spikes) and $1.44 \pm 0.28 \mathrm{~Hz}$ (range, $0-4.2 \mathrm{~Hz} ; n=131 \mathrm{HPDs}$ ), respectively. The transition between interictal clusters of isolated spikes or HPDs and postictal periods was characterized in these PF cells by a drastic increase in their firing rate (Fig. $4 B_{2}, B_{4}$ ), the end of hippocampal paroxysms being concomitant with an abrupt and transient excitation of these neurons. Before this increase of firing rate, the mean discharge frequency of PF thalamic cells during hippocampal paroxysmal events was $2.5 \pm 0.26 \mathrm{~Hz}$, whereas the rebound of excitation had a mean frequency of $11 \pm 0.68 \mathrm{~Hz}$ and lasted $2.02 \pm$ $0.12 \mathrm{~s}(n=102$ interictal clusters of isolated spikes and HPDs, 19 cells). This increase in the firing rate of PF cells concomitant with the end of hippocampal events was statistically significant $(p<0.001$; Mann-Whitney rank sum test).

The second category of PF cells $(n=11)$, which were also located within the boundaries of the PF nucleus, did not show any significant change in their firing rate between ictal and interictal periods (interictal mean frequency, $2 \pm 0.63 \mathrm{~Hz}$; range, $0.084-$ $6.58 \mathrm{~Hz}$; mean frequency during clusters of isolated spikes, $2.53 \pm 0.8 \mathrm{~Hz}$; range, $0.054-$ $8.88 \mathrm{~Hz}$; mean frequency during HPDs, $3 \pm$ $0.85 \mathrm{~Hz}$; range, $0.86-7.34 \mathrm{~Hz} ; n=11$ cells).

We found no correlation between the firing pattern and the morphology of the PF neurons.

Finally, 13 neurons located outside the PF (e.g., ventral posteromedial, centrolateral, or posterior thalamic nuclei) were recorded in the same conditions, and their firing patterns did not show any detectable correlation with hippocampal LFP and were not modified by the occurrence of HPDs (interictal mean frequency, $3.25 \pm$ $1.15 \mathrm{~Hz}$; range, $0.031-13.6 \mathrm{~Hz}$; mean frequency during clusters of isolated spikes, $3.83 \pm 1.3 \mathrm{~Hz}$; range, $0.67-15.1 \mathrm{~Hz}$; mean frequency during HPDs, $2.75 \pm 0.85 \mathrm{~Hz}$; range, 0.62-9.4 $\mathrm{Hz} ; n=13$ cells). 
Altogether, our intracellular and extracellular recordings from the PF demonstrate that the firing pattern of most of PF neurons is drastically modified by the occurrence of HPDs.

\section{Suppressive effect of high-frequency stimulation of the PF nucleus}

To test the hypothesis of a role of the PF in the control of HPDs, we then examined the effects of high-frequency stimulation (HFS) of this structure. Such stimulations are now commonly used for DBS in human patients and are suggested to result in an overall suppression of the local neuronal activity (McIntyre et al., 2004), although this effect is very much debated (Gradinaru et al., 2009). In this experiment, we tested single ipsilateral, contralateral, or bilateral $5 \mathrm{~s}$ stimulations of the PF using either monophasic and bipolar modes (frequency, $130 \mathrm{~Hz}$; pulse width, $60 \mu \mathrm{s})$ in 18 mice. In a few mice, the effects of lower frequency $(20 \mathrm{~Hz})$ were also tested to mimic the behavior of PF neurons observed at termination of HPDs.

\section{Ipsilateral stimulations}

In nine animals with both electrode tips located within the ipsilateral PF nucleus, bipolar stimulations interrupted the ongoing HPDs at a mean threshold of $25 \pm$ $1.9 \mu \mathrm{A}$. The antiepileptic and behavioral thresholds were significantly lower than the motor threshold (73 and 65\% decreases, respectively; $p=0.004$; Wilcoxon test) (Fig. 5A). A slight but not significant difference was observed between antiepileptic and behavioral thresholds $(p=$ 0.25; Wilcoxon test). Furthermore, timefrequency analysis revealed that ipsilateral $130 \mathrm{~Hz}$ stimulations of the PF at the antiepileptic threshold suppressed all oscillatory activities between 0 and $20 \mathrm{~Hz}$ at the hippocampal and cortical levels (Fig. 5C).

When a referential mode was used (monopolar stimulation with one PF electrode as the cathode and the reference electrode over the cerebellum as the anode), the thresholds were slightly increased $(\sim 6 \%)$, although no significant differences were observed (results not shown).

To investigate the specificity of the PF as a target for deep brain stimulation, we compared the thresholds for ipsilateral bipolar stimulations between sites located within the ipsilateral PF (in sites, $n=9$ ) and adjacent regions (out sites, $n=6$; namely, the posterior thalamic nuclei group, the ventral anterior pretectal nucleus, the dorsal anterior pretectal nucleus, and the periventricular fiber system) (Fig. 5D). The thresholds for antiepileptic, behavioral, and motor effects were significantly lower when stimulations were applied within the PF region $(p=0.013,0.016$, and 0.013 , respectively; Mann-Whitney test) (Fig. $5 B, D$ ). The possibility to interrupt HPDs by stimulations of adjacent regions,
C

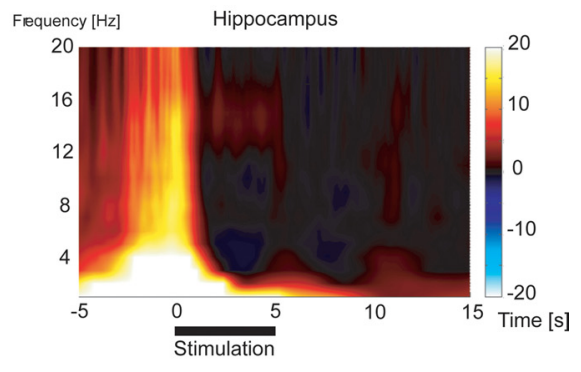

Cortex
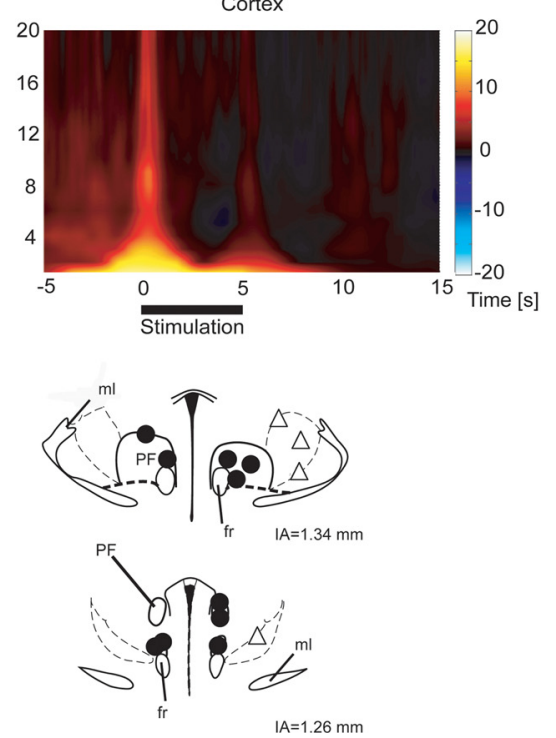

$\mid A=1.26 \mathrm{~mm}$

Figure 5. Effects of $130 \mathrm{~Hz}$ stimulation of the PF nucleus on HPDs. $\boldsymbol{A}$, Intensity thresholds according to stimulation mode: ipsilateral, contralateral, or bilateral stimulations ( $n=9,9$, and 4 mice respectively; ${ }^{*} p<0.05$, Wilcoxon test, compared with psilateral stimulation values; ${ }^{p} p<0.05$, Wilcoxon test, compared with antiepileptic threshold values). $\boldsymbol{B}$, Site specificity of PF nucleus ( $n=9$ mice inside; $n=6$ mice outside; ${ }^{*} p<0.05$, Mann-Whitney test, compared with thresholds obtained with (tions applied within the PF nucleus). C, Time-frequency chart of power averaged over hippocampal and cortical derivation struction of the electrode tip localization inside the PF nucleus (black dots) and outside the boundaries of the PF nucleus (open triangles). IA, Interaural; ml, medial lemniscus; fr, fasciculus retroflexus.

although with higher current intensities, could account for spreading phenomenons as well as the involvement of other putative neuronal networks. Similarly to intracerebral pharmacological manipulations, such a gradient effect could also be observed when stimulations were applied to other structures (Feddersen et al., 2007).

Then we tested the effect of $20 \mathrm{~Hz}$ stimulations, which corresponds to the mean firing rate of PF neurons during the rebound of excitation observed at the end of HPDs. In two mice equipped with bipolar electrodes in the ipsilateral PF, $20 \mathrm{~Hz}$ stimulation did not interrupt ongoing HPDs, whatever the amount of current applied (up to $150 \mu \mathrm{A}$ ). However, transient interruptions of HPDs were observed, which lasted the duration of the stimulation (results not shown). This suggests that $20 \mathrm{~Hz}$ stimulation of the PF interferes with HPDs without terminating them.

\section{Contralateral and bilateral stimulations}

Contralateral stimulations of the PF also interrupted ongoing HPDs $(n=9$ mice) with a mean antiepileptic threshold of $35 \pm$ 


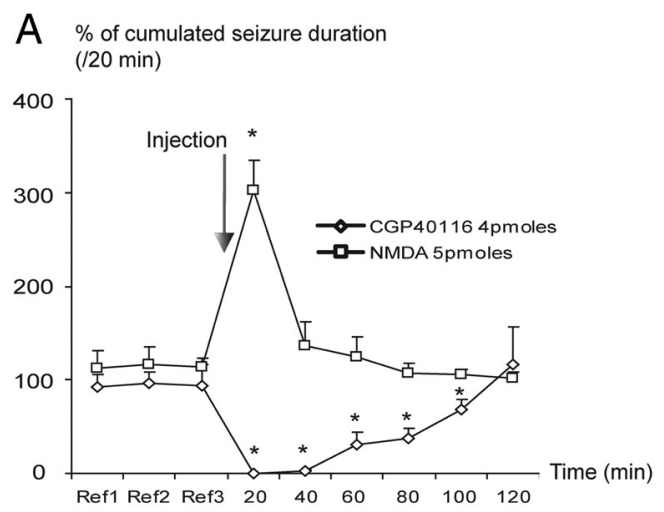

$$
\text { B Time to first seizure }
$$

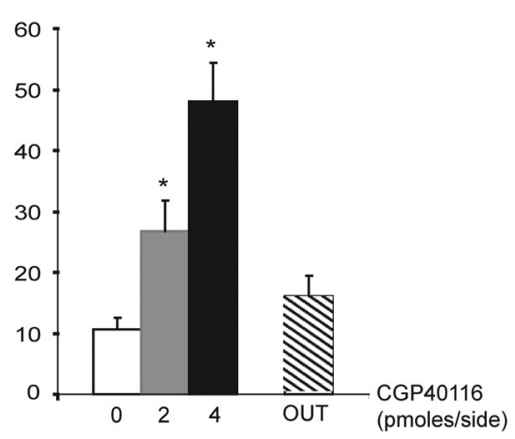

D

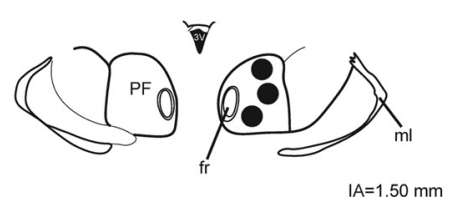

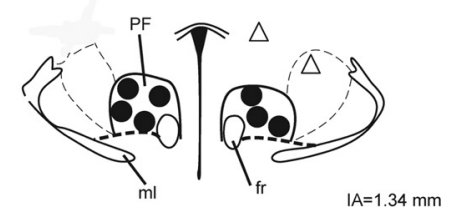

C Time to first seizure $(\min )$

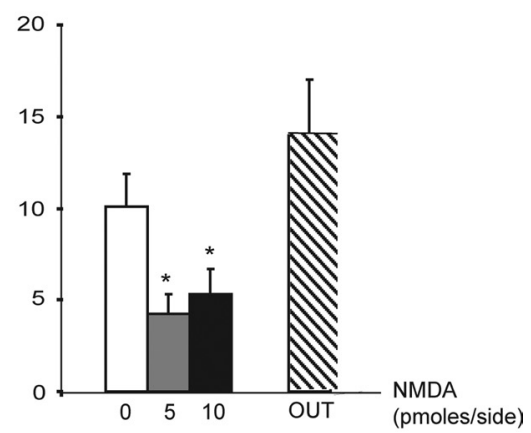

$\mathrm{A}=1.26 \mathrm{~mm}$

Figure 6. Effects of bilateral intra-PF injections of CGP40116 and NMDA on HPDs. A, Percentage (mean and SEM) of cumulated duration of HPDs per 20 min period before [reference (Ref)] and after intra-PF microinjections of (GP40116 (4 pmol/side; $n=8 ;{ }^{*} p<0.05$; Wilcoxon test) or NMDA ( 5 pmol/side; $n=9 ;{ }^{*} p<0.05$; Wilcoxon test) compared to vehicle (NaCl). $\boldsymbol{B}$, Reoccurrence latency of HPDs after vehicle ( NaCl), CGP40116 (2 and $4 \mathrm{pmol} /$ side) intra-PF microinjections, and (GP40116 ( $4 \mathrm{pmol} /$ side) injected outside the boundaries of the PF nucleus (0UT; $n=8 ;{ }^{*} p<0.05 ;$ Wilcoxon test). C, Reoccurrence latency of HPDs after vehicle (NaCl), NMDA (5 and 10 pmol/side) intra-PF microinjections, and NMDA ( 5 pmol/side) injected outside the boundaries of the PF nucleus (0UT; $n=9 ;{ }^{*} p<0.05$; Wilcoxon test). D, Example of mouse's brain coronal sections showing histological reconstruction of the microinjection sites at which bilateral intra-PFinjections of CGP40116 (2 and $4 \mathrm{pmol} /$ side) resulted in a suppression of HPDs (black dots, tips of the injection cannulae) and sites at which the same doses of (GP40116 were without effects on HPDs occurrence (open triangles). IA, Interaural; ml, medial lemniscus; fr, fasciculus retroflexus.

$3.2 \mu \mathrm{A}$ and higher behavioral $(+10 \% ; p=0.25)$ and motor thresholds $(+95 \%$; $p=0.004$; Wilcoxon test $)$. All of these thresholds were significantly higher than for ipsilateral stimulations (antiepileptic, $p=0.03$; behavioral, $p=0.006$; motor, $p=0.001$; Mann-Whitney test) (Fig. 5A). When bilateral stimulations were applied ( $n=4$ mice), bipolar $130 \mathrm{~Hz}$ stimulation interrupted HPDs with threshold values that were similar to ipsilateral stimulations $(p=0.12)$ and significantly lower than contralateral stimulations $(p=0.017)$ (Fig. $5 A)$.

\section{Effects of PF glutamatergic neurotransmission modulation on HPDs}

The PF receives strong glutamatergic inputs mainly arising from the sensorimotor cortex. To determine the potential role of this glutamatergic neurotransmission on the PF, the effects of (1) blockade and (2) potentiation of NMDA-mediated glutamatergic neurotransmission on the occurrence of HPDs were examined by local application of CGP40116 $(n=8$ mice $)$ or NMDA $(n=9$ mice $)$, respectively.

Bilateral intra-PF injection of CGP40116 (2 and 4 pmol per side) significantly suppressed the number of HPDs (data not shown) and their cumulated duration for up to $100 \mathrm{~min}$ at the highest dose (Fig. 6A), compared with the vehicle condition. During the first $40 \mathrm{~min}$ after injection, the number and cumulated duration of HPDs were decreased by $>95 \%$, compared with vehicle $(\mathrm{NaCl}$ injection, $100 \%$ ) (Fig. $6 \mathrm{~A}$ ). Ictal activity then returned to baseline (Fig. $6 A$, reference periods Ref1, Ref2, and Ref3) within $2 \mathrm{~h}$. Moreover, the latency for the reoccurrence of HPDs after drug injection was significantly increased at 2 or 4 pmol per side in a dose-dependent way (Fig. $6 B$ ). At either dose, the interictal activity in the hippocampus or in the cortex during the 0-20 and 20-40 min periods after injection was not altered as indicated by the stability of the shape of the LFP amplitude spectrum between before and after injection periods (supplemental Fig. S1 A, available at www.jneurosci.org as supplemental material).
In addition, the suppressive effects on HPDs were observed only when injections were performed inside the PF (Fig. 6D, black dots, tips of injection cannulae). In three additional animals injected outside the PF (namely, the dorsal anterior pretectal nucleus, deep mesencephalic nucleus, and ventral tegmental area), no significant effects on HPD suppression or reoccurrence latency ( $16 \pm 4$ min outside the PF vs $48 \pm 6$ min inside the PF at $4 \mathrm{pmol} / \mathrm{side}$ ) were observed (Fig. $6 \mathrm{~B}, \mathrm{D}$, open triangles).

Finally, at the doses used, no behavioral effects were observed: mice remained quiet in their test cage and explored their environment or groomed. In two mice injected with a higher dose $(8$ $\mathrm{pmol} /$ side), suppression of HPDs was observed, along with prostrations beginning within the first minutes after the injection and lasting for up to $60 \mathrm{~min}$ (results not shown).

By contrast, bilateral intra-PF injection of NMDA significantly increased by 100 and 202\%, respectively, the number (data not shown) and cumulative duration of HPDs during the first 20 min after injection of the lowest dose ( $5 \mathrm{pmol} / \mathrm{side})$ compared with vehicle injection $(\mathrm{NaCl}, 100 \%)$ (Fig. 6A). This worsening effect was mostly over (19 and 36\%, respectively) 40 min after injection and back to the baseline level, at $60 \mathrm{~min}$ after injection (Fig. 6A). No effects on the mean duration of HPDs were observed (data not shown). At this dose, no behavioral or motor side effects were observed at any time. At the highest dose of NMDA (10 pmol/side), behavioral side effects such as sniffing or exploring behaviors that clearly interfered with the occurrence of HPDs were observed. Nonetheless, the latency of reoccurrence of the first HPDs after drug injection significantly decreased after injection of both 5 and 10 pmol per side, compared with $\mathrm{NaCl}$ (Fig. 6C). However, no generalizations of the HPDs by spreading to the cortex were ever observed.

In five additional animals injected outside the boundaries of the PF (namely, the ventromedial thalamic nucleus, mediodorsal thalamic nucleus, dorsal anterior pretectal nucleus, superior cerebellar peduncle, and posterior thalamic nuclei group), no significant ef- 

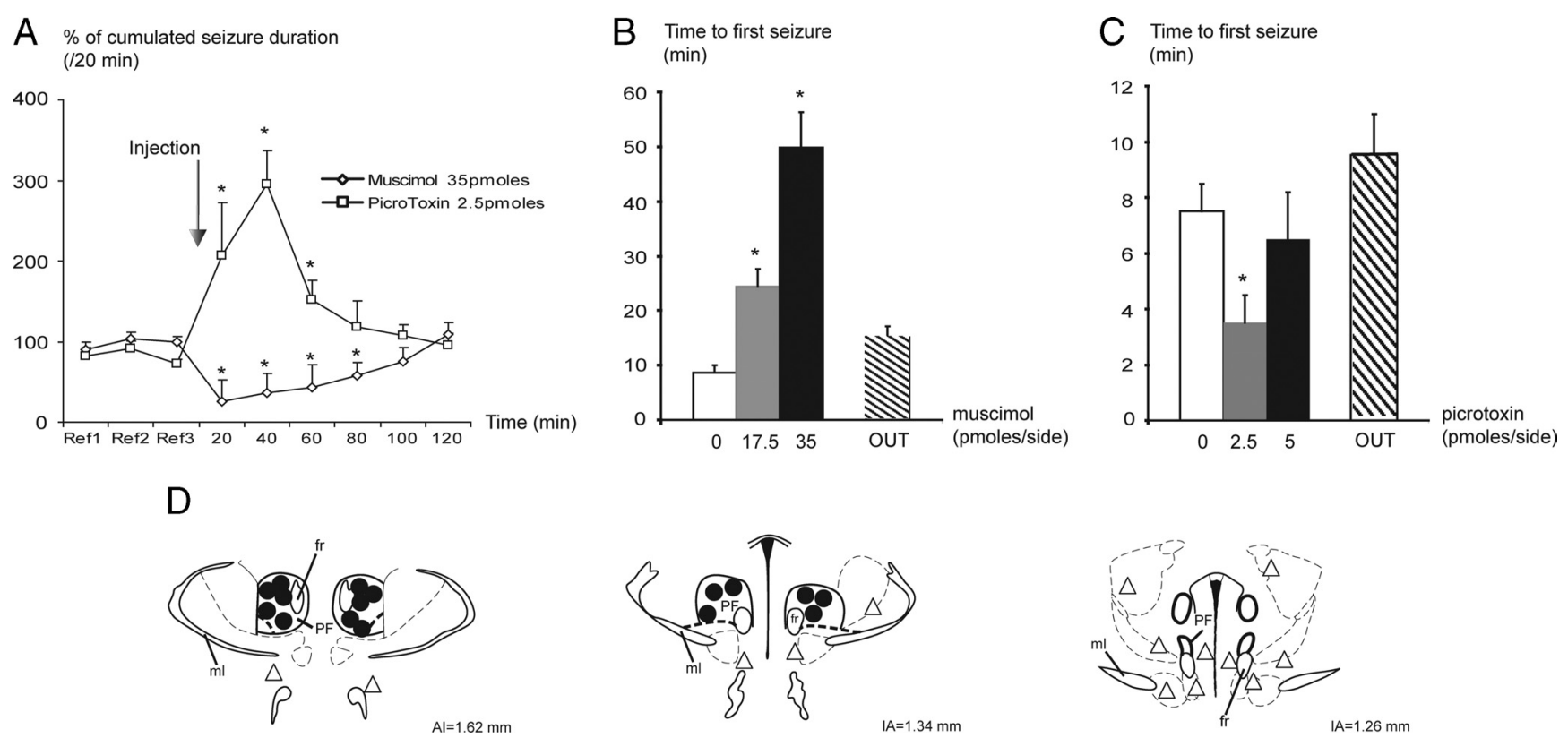

Figure 7. Effects of bilateral intra-PF injections of muscimol and picrotoxin on HPDs. $A$, Percentage (mean and SEM) of cumulated duration of HPDs per 20 min period, before [reference (Ref)] and after intra-PF microinjections of muscimol (35 pmol/side; $n=8$; ${ }^{*} p<0.05$; Wilcoxon test) or picrotoxin ( $2.5 \mathrm{pmol} / \mathrm{side} ; n=8$; ${ }^{*} p<0.05$; Wilcoxon test) compared to vehicle (NaCl). $\boldsymbol{B}$, Reoccurrence latency of HPDs after vehicle ( $\mathrm{NaCl}$ ), muscimol ( 17.5 and $35 \mathrm{pmol} / \mathrm{side}$ ) intra-PF microinjections, and muscimol ( $35 \mathrm{pmol} / \mathrm{side}$ ) injected outside the boundaries of the PF nucleus (0UT; $n=8 ;{ }^{*} p<0.05$; Wilcoxon test). C, Reoccurrence latency of HPDs after vehicle ( $\mathrm{NaCl}$ ), picrotoxin (2.5 and $5 \mathrm{pmol} / \mathrm{side}$ ) intra-PF microinjections, and picrotoxin (2.5 pmol/side) injected outside the boundaries of the PF nucleus (OUT; $n=8 ;{ }^{*} p<0.05$; Wilcoxon test). $\boldsymbol{D}$, Example of mouse's brain coronal sections showing histological reconstruction of the microinjection sites at which bilateral intra-PF injections of muscimol (17.5 and $35 \mathrm{pmol} /$ side) resulted in a suppression of HPDs (black dots, tips of the injection cannulae) and sites at which the same doses of muscimol were without effects on HPDs occurrence (open triangles). IA, Interaural; ml, medial lemniscus; fr, fasciculus retroflexus.

fects on HPD suppression or reoccurrence latency (14 $\pm 3 \mathrm{~min}$ outside vs $4 \pm 1 \mathrm{~min}$ inside at $5 \mathrm{pmol} / \mathrm{side}$ ) were observed (Fig. $6 C$ ).

\section{Effects of PF GABAergic neurotransmission modulation on HPDs}

To determine the potential role of GABAergic neurotransmission from the basal ganglia structures (mainly the $\mathrm{SNr}$ ) on the PF neurons, the effects of (1) potentiation and (2) blockade of $\mathrm{GABA}_{\mathrm{A}}$-mediated neurotransmission were examined by local applications of muscimol $(n=8)$ or picrotoxin $(n=8)$, respectively.

Bilateral intra-PF injection of muscimol (17.5 and 35 pmol per side) significantly suppressed the number of HPDs (data not shown) and their cumulated duration for up to $80 \mathrm{~min}$ at the highest dose, compared with vehicle injection (Fig. 7A). At the lowest dose, bilateral injection of muscimol induced a significant suppression in the number of HPDs for $40 \mathrm{~min}$ and a significant decrease in cumulated duration for $20 \mathrm{~min}$ after injection, compared with vehicle injection (data not shown). At the highest dose, the number and cumulated duration of HPDs decreased by $>90 \%$ during the first $20 \mathrm{~min}$ period after injection, compared with the vehicle condition $(\mathrm{NaCl}, 100 \%)$ (Fig. 7A). It then progressively returned to baseline within $2 \mathrm{~h}$. Moreover, the latency for the reoccurrence of HPDs after drug injection increased significantly at 17.5 or 35 pmol per side in a dosedependent way (Fig. $7 B$ ). At either dose, the interictal activity in the hippocampus or the cortex during the 0-20 and 20-40 min periods after injection was not altered, as indicated by the stability of the shape of the LFP amplitude spectrum between preinjection and postinjection periods (supplemental Fig. S1B, available at www. jneurosci.org as supplemental material).

In addition, the suppressive effects were observed only when injections were performed within the PF (Fig. $7 B, D$, black dots, tips of injection cannulae). In seven additional animals injected outside the PF (namely, in the superior cerebellar peduncle, ventromedial thalamic nucleus, posterior hypothalamic area, periacqueductal gray, lateral hypothalamic area, deep mesencephalic nucleus, and ventral tegmental area), no significant effects on HPD suppression or reoccurrence latency $(15 \pm 2$ min outside the PF vs $50 \pm 6$ inside the PF at $35 \mathrm{pmol} / \mathrm{side}$ ) were observed (Fig. $7 B, D$, open triangles).

Finally, at the doses used, no behavioral effects were observed. In two mice injected with a higher dose of muscimol (70 pmol/ side), behavioral and motor side effects such as forelimb stereotypies in upright position and rotations were observed, beginning within the first minutes after the injection and lasting for up to 60 min. In this case, LFP recordings were contaminated by movement artifacts.

Bilateral intra-PF injection of picrotoxin induced a significant increase in the number and cumulative duration of HPDs during the first hour after injection at the lowest dose $(2.5 \mathrm{pmol} / \mathrm{side})$ (Fig. 7A). The cumulated durations of HPDs were worsened by 107,195 , and $52 \%$ at 20,40 , and 60 min, respectively, compared with vehicle $(\mathrm{NaCl}, 100 \%)$ (Fig. $7 A$ ). The latency for the reoccurrence of HPDs after drug injection significantly increased at 2.5 $\mathrm{pmol} / \mathrm{side}$ (Fig. 7C). At this dose, neither behavioral nor motor side effects were observed. At the dose of $5 \mathrm{pmol} / \mathrm{side}$, picrotoxin also induced an aggravation in both the number and cumulated duration of HPDs (35 and 42\%, respectively, between 40 and 60 min after injection) lasting up to $60 \mathrm{~min}$. However, at this dose, motor side effects that interfered with the occurrence of HPDs were noticed, but no generalizations of the HPDs by spreading to the cortex were ever observed. In four additional animals injected outside the boundaries of the PF (namely, in the lateral habenular nucleus, ethmoid nucleus, dorsal anterior pretectal nucleus, subcommissural nucleus), no significant effects on HPD suppression 
or reoccurrence latency ( $10 \pm 2$ min outside the PF vs $4 \pm 1$ inside the $\mathrm{PF}$ at $2.5 \mathrm{pmol} / \mathrm{side}$ ) were observed (Fig. $7 \mathrm{C}$ ).

\section{Discussion}

We showed here that (1) PF neurons are hyperpolarized during HPDs and fire synchronously just before the end of the HPDs, (2) HFS of this structure interrupts ongoing HPDs, and (3) pharmacological inhibition or activation of the PF neurons respectively suppresses or aggravates HPDs. These data suggest that the PF plays a role in the control of focal hippocampal seizures in MTLE.

\section{Hippocampal neuronal activity during HPDs}

This study provides the first description of the intracellular activity of hippocampal neurons during spontaneous HPDs in vivo. Recorded neurons in the CA1 region could be either pyramidal neurons or granule cells. Indeed, very few $\mathrm{CA} 1, \mathrm{CA} 3$, and hilar neurons are still present 2-3 weeks after KA injection, whereas granule cells are dispersed in the dorsal hippocampus (Riban et al., 2002). However, the interictal firing profile of hippocampal cells closely resembles that observed in vitro in identified pyramidal neurons from a similar mouse model (Le Duigou et al., 2008). It is also consistent with the "paroxysmal depolarization shift" described in vitro from other animal models and human tissue (Tancredi et al., 1990; Smith et al., 1998; Huberfeld et al., 2008). The intracellular events underlying the spontaneous occurrence of HPDs are composed of a sustained membrane depolarization on which rhythmic depolarizations crowned by action potentials are superimposed. Although this exacerbated neuronal activity shares some features with that found in vivo in pyramidal cells during cortical seizures, additional investigations will be required to determine the specific synaptic and intrinsic mechanisms underlying the intracellular paroxysmal activity in hippocampal cell (Giaretta et al., 1987; Steriade et al., 1998).

\section{How are PF neurons influenced during HPDs?}

LFP and intracellular recordings in the PF indicate that although PF neurons do not actively initiate HPDs, their activity is drastically modulated by these events. The amplitude of the hyperpolarization of PF neurons during HPDs did not change when the membrane potential was maintained at different levels of polarization by DC injection and could not be reversed in polarity when it was hold at hyperpolarized potential (less than $-80 \mathrm{mV}$ ). This may result from a disfacilitation of glutamatergic inputs or from a shunting inhibition of PF neurons originating from the $\mathrm{nRT}$ or the $\mathrm{SNr}$, which receives fibers from the hippocampus and targets the distal dendrites of PF neurons (Tsumori et al., 2002).

The brief suprathreshold depolarization of PF neurons just before the termination of HPDs results from a barrage of depolarizing postsynaptic potentials, possibly amplified by the decrease in the SNr cells activity (Deransart et al., 2003; Paz et al., 2007). Indeed, suppression of HPDs was observed in MTLE mice after intranigral injection of muscimol (Deransart and Depaulis, 2004). The reduced activity of inhibitory nigral projections onto PF cells might resume the hyperpolarization of the thalamic neurons and facilitate the dendritic summation and propagation of their excitatory postsynaptic potentials.

\section{Is the PF involved in the interruption of HPDs?}

The short change in activity observed in a majority of PF neurons within the last second of HPDs strongly suggests the involvement of this structure in the active termination of seizures. This supports the general concept that subcortical circuits play a role in the modulation of epileptic seizures (Deransart and Depaulis,
2002). The involvement of the PF in a subcortical circuit modulating seizures is confirmed by the suppression of HPDs observed after HFS or pharmacological manipulations. Because of the small number of structures injected or stimulated outside of the $\mathrm{PF}$ in each group, we cannot provide statistical analysis, but it is possible that hippocampal activity after injections or stimulations in the PF may be different from that in outside structures. Data of the midline thalamus and the mediodorsal and reuniens nuclei support this hypothesis suggesting their participation in the initiation and spread of limbic seizures (Cassidy and Gale, 1998; Bertram et al., 2001, 2008).

Our data suggest that HPD suppression follows drug infusions that may hyperpolarize PF neurons (muscimol or CGP40116), whereas they are aggravated by drugs (picrotoxin, NMDA) that likely result in depolarization. However, the local injection of muscimol may also facilitate synchronization of PF neurons and therefore facilitate the regular occurrence of bursts of action potentials (Liu et al., 1992; Cope et al., 2005). The frequency of such bursts could be critical in HPD suppression, as $130 \mathrm{~Hz}$ stimulations were effective but $20 \mathrm{~Hz}$ were not. Data dealing with the precise effect of locally applied drugs on the PF cells' activity, and hence on fibers of passage, are missing from the available literature. Further experiments coupling local drug application with intracellular recordings thus remain necessary to precisely understand how our electrophysiological data fit with our stimulation and pharmacological data.

\section{Which circuits mediate the modulatory effects of the PF over HPDs?}

No monosynaptic projection from the PF to the hippocampus has been confirmed in recent studies (Wyss et al., 1979; Van der Werf et al., 2002). Therefore, the increased activity in PF neurons, as well as the suppressive or worsening effects on HPDs, very likely involves the cerebral cortex or subcortical structures as the basal ganglia or the nRT. Our data suggest that the PF exerts a control over the hippocampus via a modulation of cortical synchronization. Indeed, time-frequency analysis of LFPs recordings revealed that synchronous oscillatory activity in the 10-20 $\mathrm{Hz}$ frequency band also increased in the sensorimotor cortex during the last second of HPDs. These data are consistent with the role of the PF in the modulation of many physiological oscillatory activities that could interfere with the pathological synchronous oscillations in the hippocampus (Glenn and Steriade, 1982; Dahl and Winson, 1986; Pavlides et al., 1987; Steriade et al., 1991; Seidenbecher and Pape, 2001; Lacey et al., 2007). Connections from the PF nucleus to the entorhinal cortex have been described and are likely to be involved in these modulatory effects (Berendse and Groenewegen, 1991). The fact that HFS of the PF interrupts ongoing HPDs with a greater efficacy when applied ipsilaterally to the injected hippocampus is in agreement with anatomical studies describing projections of the PF as mainly ipsilateral (Vercelli et al., 2003). However, cross talk between the two PF nuclei through the nRT has also been described (Raos and Bentivoglio, 1993; Kolmac and Mitrofanis, 1997). This could explain the interruption of HPDs, although less effective, when stimulation was applied on the contralateral side, and why bilateral stimulations were not more efficient to stop HPDs.

The control of the PF over the HPDs might also be mediated through the basal ganglia (McHaffie et al., 2005). The PF could mediate its antiepileptic effects through its diffuse projections to the striatum and the subthalamic nucleus by impinging on the activity of the $\mathrm{SNr}$, a structure modulating seizures in MTLE mice (Deransart and Depaulis, 2004). In a genetic model of absence epilepsy, striatal output neurons were shown to be silent during 
the paroxysmal activities and to exhibit a rebound firing at the end of the ictal discharges (Slaght et al., 2004). The transient interruption of firing, similar to that of PF neurons in our model, presumably decreases the synaptic inhibition on $\mathrm{SNr}$ neurons and modifies the balance between synaptic inhibition and excitation, tending to reinforce the actions of excitatory synaptic inputs arising from the subthalamic nucleus (Kita, 1994). Whether the transient burst of action potentials observed in the PF at the end of HPD triggers striatal neurons or is triggered by nigral ones will require further electrophysiological studies.

\section{The PF nucleus: a potential therapeutic target for focal seizures?}

Both drug applications and HFS in the PF reduced the occurrence of HPDs without affecting their LFP pattern, mean duration or background EEG activity and could be obtained without behavioral side effects. This suggests that such manipulations act on the ability of the hippocampus to generate HPDs rather than on changing their EEG characteristics. Our pharmacological data also suggest that the antiepileptic effects of $130 \mathrm{~Hz}$ stimulation of the PF are rather associated with neuronal inhibition, in agreement with several studies, although this question still remains debated (Urbano et al., 2002; McIntyre et al., 2004). However, imposing a frequency that strongly differs from that observed intrinsically during HPDs may also explain the antiepileptic effects observed (Garcia et al., 2005; Hammond et al., 2008).

We also showed that the modulation of seizures is specific to the PF. It may therefore constitute an interesting target for therapeutic DBS in patients with drug-resistant seizures. This is in agreement with several clinical studies where HFS of the CM/PF reduced and even abolished generalized seizures in patients with Lennox-Gastaut syndrome, an effect thought to be related to the activation of ipsilateral desynchronizing thalamocortical projections (Velasco et al., 2000, 2006). Our present study thus provides new hypothesis to explain the antiepileptic effects of DBS applied to the CM/PF in human.

Altogether, our data suggest that the PF can influence the generation of seizures in the hippocampus. The synchronized oscillations and the increased firing rate of PF neurons at the end of HPDs require further investigations to understand its role in the termination of seizures.

\section{References}

Berendse HW, Groenewegen HJ (1991) Restricted cortical termination fields of the midline and intralaminar thalamic nuclei in the rat. Neuroscience 42:73-102.

Bertram EH, Mangan PS, Zhang DX, Scott CA, Williamson JM (2001) The midline thalamus: alterations and a potential role in limbic epilepsy. Epilepsia 42:967-978.

Bertram EH, Zhang D, Williamson JM (2008) Multiple roles of midline dorsal thalamic nuclei in induction and spread of limbic seizures. Epilepsia 49:256-268.

Cassidy RM, Gale K (1998) Mediodorsal thalamus plays a critical role in the development of limbic motor seizures. J Neurosci 18:9002-9008.

Cendes F, Kahane P, Brodie M, Andermann F (2002) The mesio-temporal lobe epilepsy syndrome. In: Epileptic syndromes in infancy, childhood and adolescence (Roger J, Bureau M, Dravet C, Genton P, Tassinari CA, Wolf P, eds), pp 513-530. Eastleigh, UK: John Libbey.

Chabardès S, Kahane P, Minotti L, Tassi L, Grand S, Hoffmann D, Benabid AL (2005) The temporopolar cortex plays a pivotal role in temporal lobe seizures. Brain 128:1818-1831.

Charpier S, Leresche N, Deniau JM, Mahon S, Hughes SW, Crunelli V (1999) On the putative contribution of $\mathrm{GABA}(\mathrm{B})$ receptors to the electrical events occurring during spontaneous spike and wave discharges. Neuropharmacology 38:1699-1706.
Cope DW, Hughes SW, Crunelli V (2005) GABAA receptor-mediated tonic inhibition in thalamic neurons. J Neurosci 25:11553-11563.

Dahl D, Winson J (1986) Influence of neurons of the parafascicular region on neuronal transmission from perforant pathway through dentate gyrus. Brain Research 377:391-396.

Deransart C, Depaulis A (2002) The control of seizures by the basal ganglia? A review of experimental data. Epileptic Disord 4 [Suppl 3]:S61-S72.

Deransart C, Depaulis A (2004) Le concept de contrôle nigral des épilepsies s'applique-t-il aux épilepsies partielles pharmacorésistantes? Epilepsies 16:75-82.

Deransart C, Marescaux C, Depaulis A (1996) Involvement of nigral glutamatergic inputs in the control of seizures in a genetic model of absence epilepsy in the rat. Neuroscience 71:721-728.

Deransart C, Lê BT, Marescaux C, Depaulis A (1998) Role of the subthalamo-nigral input in the control of amygdala-kindled seizures in the rat. Brain Res 807:78-83.

Deransart C, Riban V, Lê BT, Hechler V, Marescaux C, Depaulis A (1999) Evidence for the involvement of the pallidum in the modulation of seizures in a genetic model of absence epilepsy in the rat. Neurosci Lett 265:131-134.

Deransart C, Hellwig B, Heupel-Reuter M, Léger JF, Heck D, Lücking CH (2003) Single-unit analysis of substantia nigra pars reticulata neurons in freely behaving rats with genetic absence epilepsy. Epilepsia 44:15131520.

Deschênes M, Bourassa J, Doan VD, Parent A (1996) A single-cell study of the axonal projections arising from the posterior intralaminar thalamic nuclei in the rat. Eur J Neurosci 8:329-343.

Engel J Jr (1996) Introduction to temporal lobe epilepsy. Epilepsy Res 26:141-150.

Feddersen B, Vercueil L, Noachtar S, David O, Depaulis A, Deransart C (2007) Controlling seizures is not controlling epilepsy: a parametric study of deep brain stimulation for epilepsy. Neurobiol Dis 27:292-300.

Garcia L, D’Alessandro G, Fernagut PO, Bioulac B, Hammond C (2005) Impact of high- frequency stimulation parameters on the pattern of discharge of subthalamic neurons. J Neurophysiol 94:3662-3669.

Giaretta D, Avoli M, Gloor P (1987) Intracellular recordings in pericruciate neurons during spike and wave discharges of feline generalized penicillin epilepsy. Brain Res 405:68-79.

Glenn LL, Steriade M (1982) Discharge rate and excitability of cortically projecting intralaminar thalamic neurons during waking and sleep states. J Neurosci 2:1387-1404.

Gradinaru V, Mogri M, Thompson KR, Henderson JM, Deisseroth K (2009) Optical deconstruction of parkinsonian neural circuitry. Science 324: 354-359.

Groenewegen HJ, Berendse HW (1994) The specificity of the "nonspecific" midline and intralaminar thalamic nuclei. Trends Neurosci 17:52-57.

Hammond C, Ammari R, Bioulac B, Garcia L (2008) Latest view on the mechanism of action of deep brain stimulation. Mov Disord 23:2111-2121.

Heinrich C, Nitta N, Flubacher A, Müller M, Fahrner A, Kirsch M, Freiman T, Suzuki F, Depaulis A, Frotscher M, Haas CA (2006) Reelin deficiency and displacement of mature neurons, but not neurogenesis, underlie the formation of granule cell dispersion in the epileptic hippocampus. J Neurosci 26:4701-4713.

Henze DA, Buzsáki G (2001) Action potential threshold of hippocampal pyramidal cells in vivo is increased by recent spiking activity. Neuroscience 105:121-130.

Huberfeld G, Clemenceau S, Cohen I, Pallud J, Wittner L, Navarro V, Baulac M, Miles R (2008) Epileptiform activities generated in vitro by human temporal lobe tissue. Neurochirurgie 54:148-158.

Jahnsen H, Llinás R (1984) Electrophysiological properties of guinea-pig thalamic neurones: an in vitro study. J Physiol 349:205-226.

Kita H (1994) Parvalbumin-immunopositive neurons in rat globus pallidus: a light and electron microscopic study. Brain Res 657:31-41.

Kolmac CI, Mitrofanis J (1997) Organisation of the reticular thalamic projection to the intralaminar and midline nuclei in rats. J Comp Neurol 377:165-178.

Lacey CJ, Bolam JP, Magill PJ (2007) Novel and distinct operational principles of intralaminar thalamic neurons and their striatal projections. J Neurosci 27:4374-4384.

Le Duigou C, Bouilleret V, Miles R (2008) Epileptiform activities in slices of 
hippocampus from mice after intra-hippocampal injection of kainic acid. J Physiol 586:4891-4904.

Le Van Quyen M, Foucher J, Lachaux J, Rodriguez E, Lutz A, Martinerie J, Varela FJ (2001) Comparison of Hilbert transform and wavelet methods for the analysis of neuronal synchrony. J Neurosci Methods 111:83-98.

Liu C, Wang Y, Smallwood PM, Nathans J (2008) An essential role for Frizzled5 in neuronal survival in the parafascicular nucleus of the thalamus. J Neurosci 28:5641-5653.

Liu Z, Vergnes M, Depaulis A, Marescaux C (1992) Involvement of intrathalamic $\mathrm{GABAB}$ neurotransmission in the control of absence seizures in the rat. Neuroscience 48:87-93.

Mahon S, Casassus G, Mulle C, Charpier S (2003) Spike-dependent intrinsic plasticity increases firing probability in rat striatal neurons in vivo. J Physiol 550:947-959.

McHaffie JG, Stanford TR, Stein BE, Coizet V, Redgrave P (2005) Subcortical loops through the basal ganglia. Trends Neurosci 28:401-407.

McIntyre CC, Savasta M, Kerkerian-Le Goff L, Vitek JL (2004) Uncovering the mechanism(s) of action of deep brain stimulation: activation, inhibition, or both. Clin Neurophysiol 115:1239-1248.

Meier R, Häussler U, Aertsen A, Deransart C, Depaulis A, Egert U (2007) Short-term changes in bilateral hippocampal coherence precede epileptiform events. NeuroImage 38:138-149.

Mouroux M, Hassani OK, Féger J (1995) Electrophysiological study of the excitatory parafascicular projection to the subthalamic nucleus and evidence for ipsi- and contralateral controls. Neuroscience 67:399-407.

Nail-Boucherie K, Lê-Pham BT, Gobaille S, Maitre M, Aunis D, Depaulis A (2005) Evidence for a role of the parafascicular nucleus of the thalamus in the control of epileptic seizures by the superior colliculus. Epilepsia 46:141-145.

Ojemann GA (1987) Surgical therapy for medically intractable epilepsy. J Neurosurg 66:489-499.

Pavlides C, Aoki C, Chen JS, Bailey WH, Winson J (1987) Differential glucose utilization in the parafascicular region during slow-wave sleep, the still-alert state and locomotion. Brain Res 423:399-402.

Paxinos G, Franklin KB (2001) The mouse brain in stereotaxic coordinates, Ed 2. Academic, New York.

Paz JT, Chavez M, Saillet S, Deniau JM, Charpier S (2007) Activity of ventral medial thalamic neurons during absence seizures and modulation of cortical paroxysms by the nigrothalamic pathway. J Neurosci 27:929-941.

Pinault D (1996) A novel single-cell staining procedure performed in vivo under electrophysiological control: morpho-functional features of juxtacellularly labeled thalamic cells and other central neurons with biocytin or Neurobiotin. J Neurosci Methods 65:113-136.

Rall W (1969) Time constants and electrotonic length of membrane cylinders and neurons. Biophys J 9:1483-1508.

Raos V, Bentivoglio M (1993) Crosstalk between the two sides of the thalamus through the reticular nucleus: a retrograde and anterograde tracing study in the rat. J Comp Neurol 332:145-154.

Riban V, Bouilleret V, Pham-Lê BT, Fritschy JM, Marescaux C, Depaulis A (2002) Evolution of hippocampal epileptic activity during the development of hippocampal sclerosis in a mouse model of temporal lobe epilepsy. Neuroscience 112:101-111.

Saadé NE, Al Amin H, Abdel Baki S, Chalouhi S, Jabbur SJ, Atweh SF (2007) Reversible attenuation of neuropathic-like manifestations in rats by lesions or local blocks of the intralaminar or the medial thalamic nuclei. Exp Neurol 204:205-219.

Schiff ND, Giacino JT, Kalmar K, Victor JD, Baker K, Gerber M, Fritz B, Eisenberg B, Biondi T, O'Connor J, Kobylarz EJ, Farris S, Machado A, McCagg C, Plum F, Fins JJ, Rezai AR (2007) Behavioral improvements with thalamic stimulation after severe traumatic brain injury. Nature 448:600-604

Seidenbecher T, Pape HC (2001) Contribution of intralaminar thalamic nuclei to spike-and-wave-discharges during spontaneous seizures in a genetic rat model of absence epilepsy. Eur J Neurosci 13:1537-1546.

Siegel S (1956) Nonparametric statistics for the behavioral sciences. Tokyo: McGraw-Hill Kogakusha.

Slaght SJ, Leresche N, Deniau JM, Crunelli V, Charpier S (2002) Activity of thalamic reticular neurons during spontaneous genetically determined spike and wave discharges. J Neurosci 22:2323-2334.

Slaght SJ, Paz T, Chavez M, Deniau JM, Mahon S, Charpier S (2004) On the activity of the corticostriatal networks during spike-and-wave discharges in a genetic model of absence epilepsy. J Neurosci 24:6816-6825.

Smith KL, Lee CL, Swann JW (1998) Local circuit abnormalities in chronically epileptic rats after intrahippocampal tetanus toxin injection in infancy. J Neurophysiol 79:106-116.

Smith Y, Raju DV, Pare JF, Sidibe M (2004) The thalamostriatal system: a highly specific network of the basal ganglia circuitry. Trends Neurosci 27:520-527.

Steriade M, Dossi RC, Nuñez A (1991) Network modulation of a slow intrinsic oscillation of cat thalamocortical neurons implicated in sleep delta waves: cortically induced synchronization and brainstem cholinergic suppression. J Neurosci 11:3200-3217.

Steriade M, Amzica F, Neckelmann D, Timofeev I (1998) Spike-wave complexes and fast components of cortically generated seizures. II. Extra- and intracellular patterns. J Neurophysiol 80:1456-1479.

Suzuki F, Junier MP, Guilhem D, Sørensen JC, Onteniente B (1995) Morphogenetic effect of kainate on adult hippocampal neurons associated with a prolonged expression of brain-derived neurotrophic factor. Neuroscience 64:665-674.

Tancredi V, Hwa GG, Zona C, Brancati A, Avoli M (1990) Low magnesium epileptogenesis in the rat hippocampal slice: electrophysiological and pharmacological features. Brain Res 511:280-290.

Tsumori T, Yokota S, Ono K, Yasui Y (2002) Synaptic organization of GABAergic projections from the substantia nigra pars reticulata and the reticular thalamic nucleus to the parafascicular thalamic nucleus in the rat. Brain Res 957:231-241.

Urbano FJ, Leznik E, Llinas RR (2002) Cortical activation patterns evoked by afferent axons stimuli at different frequencies: an in vitro voltagesensitive dye imaging study. Thalamus Rel Syst 1:371-378.

Van der Werf YD, Witter MP, Groenewegen HJ (2002) The intralaminar and midline nuclei of the thalamus. Anatomical and functional evidence for participation in processes of arousal and awareness. Brain Res Rev 39:107-140.

Velasco AL, Velasco F, Jiménez F, Velasco M, Castro G, Carrillo-Ruiz JD, Fanghänel G, Boleaga B (2006) Neuromodulation of the centromedian thalamic nuclei in the treatment of generalized seizures and the improvement of the quality of life in patients with Lennox-Gastaut syndrome. Epilepsia 47:1203-1212.

Velasco M, Velasco F, Velasco AL, Jiménez F, Brito F, Márquez I (2000) Acute and chronic electrical stimulation of the centromedian thalamic nucleus: modulation of reticulo-cortical systems and predictor factors for generalized seizure control. Arch Med Res 31:304-315.

Velasco M, Velasco F, Velasco AL (2001) Centromedian thalamic and hippocampal electrical stimulation for the control of intractable epileptic seizures. Clin Neurophysiol 18:1-15.

Velasco M, Eugenia-Díaz-de Leon A, Márquez I, Brito F, Carrillo-Ruiz JD, Velasco AL, Velasco F (2002) Temporo-spatial correlations between scalp and centromedian thalamic EEG activities of stage II slow wave sleep in patients with generalized seizures of the cryptogenic Lennox-Gastaut syndrome. Clin Neurophysiol 113:25-32.

Velísek L, Velísková J, Moshé SL (2002) Electrical stimulation of substantia nigra pars reticulata is anticonvulsant in adult and young male rats. Exp Neurol 173:145-152.

Vercelli A, Marini G, Tredici G (2003) Anatomical organization of the telencephalic connections of the parafascicular nucleus in adult and developing rats. Eur J Neurosci 18:275-289.

Vercueil L, Benazzouz A, Deransart C, Bressand K, Marescaux C, Depaulis A, Benabid AL (1998) High-frequency stimulation of the subthalamic nucleus suppresses absence seizures in the rat: comparison with neurotoxic lesions. Epilepsy Res 31:39-46.

Wieser HG (2004) ILAE Commission Report. Mesial temporal lobe epilepsy with hippocampal sclerosis. Epilepsia 45:695-714.

Wyss JM, Swanson LW, Cowan WM (1979) A study of subcortical afferents to the hippocampal formation in the rat. Neuroscience 4:463-476. 